\title{
HIV-1 capsid variability: viral exploitation and evasion of capsid-binding molecules
}

\author{
Akatsuki Saito ${ }^{1,2}$ [D and Masahiro Yamashita ${ }^{3^{*}}$ (1)
}

\begin{abstract}
The HIV-1 capsid, a conical shell encasing viral nucleoprotein complexes, is involved in multiple post-entry processes during viral replication. Many host factors can directly bind to the HIV-1 capsid protein (CA) and either promote or prevent HIV-1 infection. The viral capsid is currently being explored as a novel target for therapeutic interventions. In the past few decades, significant progress has been made in our understanding of the capsid-host interactions and mechanisms of action of capsid-targeting antivirals. At the same time, a large number of different viral capsids, which derive from many HIV-1 mutants, naturally occurring variants, or diverse lentiviruses, have been characterized for their interactions with capsid-binding molecules in great detail utilizing various experimental techniques. This review provides an overview of how sequence variation in CA influences phenotypic properties of HIV-1. We will focus on sequence differences that alter capsid-host interactions and give a brief account of drug resistant mutations in CA and their mutational effects on viral phenotypes. Increased knowledge of the sequence-function relationship of CA helps us deepen our understanding of the adaptive potential of the viral capsid.
\end{abstract}

Keywords: HIV-1, Lentiviruses, Capsid, Host factors, Inhibitors, Sequence variation

\section{Introduction}

The HIV-1 capsid is a conical shell that encases viral nucleoprotein complexes necessary for replication [1]. The capsid protein (CA), the major building unit of the viral capsid, is part of the precursor Gag protein in immature particles and liberated upon Gag cleavage to form mature capsids. CA-CA interactions play a critical role during virion morphogenesis [2, 3]. The mature capsid, which is composed of around 250 CA hexamers and $12 \mathrm{CA}$ pentamers, orchestrates multiple post-entry processes, including reverse transcription, nuclear entry and integration targeting $[1,4-6]$. These capsid-mediated events depend on capsid disassembly, a highly coordinated process that needs to be executed in a temporally and spatially controlled manner for optimal infectivity [7, 8]. The HIV-1 capsid directly interacts with multiple host

\footnotetext{
*Correspondence: my2661@cumc.columbia.edu

${ }^{3}$ Aaron Diamond AIDS Research Center, Columbia University Vagelos College of Physicians and Surgeons, New York, NY, USA

Full list of author information is available at the end of the article
}

factors that can either promote or thwart virus infection [9]. The complex interplay between HIV-1 capsid and cellular factors defines the fate of incoming virus particles in target cells.

Over the last two decades, an increasing number of cellular factors that bind to the HIV-1 capsid have been discovered and extensively studied in detail [9-11]. In the meantime, a number of small-molecule compounds were developed that target the capsid and block HIV-1 infection with different mechanisms of action [12, 13]. Previous studies aimed at investigating the consequence of capsid interactions with these molecules have advanced our understanding of the fundamental principles of capsid-mediated processes during HIV-1 replication. These studies employed a variety of techniques from multiple disciplines and assessed a diverse set of lentiviral capsids. These efforts have led to the accumulation of a large amount of data on the sequence-fitness landscape of the HIV-1 capsid, and provided the detailed knowledge of phenotypic outcomes caused by mutations or sequence variation in CA. original author(s) and the source, provide a link to the Creative Commons licence, and indicate if changes were made. The images or other third party material in this article are included in the article's Creative Commons licence, unless indicated otherwise in a credit line to the material. If material is not included in the article's Creative Commons licence and your intended use is not permitted by statutory regulation or exceeds the permitted use, you will need to obtain permission directly from the copyright holder. To view a copy of this licence, visit http://creativecommons.org/licenses/by/4.0/. The Creative Commons Public Domain Dedication waiver (http://creativeco mmons.org/publicdomain/zero/1.0/) applies to the data made available in this article, unless otherwise stated in a credit line to the data. 
Table 1 List of well characterized capsid mutants

\begin{tabular}{|c|c|c|c|}
\hline CA mutation & Phenotype & Location & References \\
\hline Q4R & $\begin{array}{l}\text { Decreased CPSF6 binding } \\
\text { Renders an IFN-hypersensitive virus resistant to IFN- } \beta \\
\text { Accelerates both reverse transcription and uncoating }\end{array}$ & $\beta$-hairpin & {$[139,221]$} \\
\hline R18G & $\begin{array}{l}\text { Defects in reverse transcription and infectivity } \\
\text { Loss of IP6 binding }\end{array}$ & Helix 1 & [24] \\
\hline P38A & Hypostable core & Helix 2 & {$[22,61]$} \\
\hline E45A & $\begin{array}{l}\text { Hyperstable core } \\
\text { Cell cycle dependency }\end{array}$ & Helix 2 & {$[22,61]$} \\
\hline N57A & $\begin{array}{l}\text { Loss of CPSF6 binding } \\
\text { Loss of PF74 sensitivity } \\
\text { Cell cycle dependency }\end{array}$ & Helix 3 & [22] \\
\hline Q63A/Q67A & $\begin{array}{l}\text { Hypostable core } \\
\text { Cell cycle dependency }\end{array}$ & Helix 4 & {$[22,61]$} \\
\hline N74D & $\begin{array}{l}\text { Loss of CPSF6 binding } \\
\text { Replication defect in macrophages } \\
\text { MX2 resistance } \\
\text { Integrates into gene-poor regions } \\
\text { Utilization of non-canonical nuclear entry pathway } \\
\text { Higher sensitivity to IFN-a } \\
\text { Stimulates a type I IFN response in macrophages } \\
\text { Sensitive to restriction by TRIM34 }\end{array}$ & Helix 4 & [93] \\
\hline A77V & $\begin{array}{l}\text { Loss of CPSF6 binding } \\
\text { Integrates into gene-poor regions }\end{array}$ & Helix 4 & [199] \\
\hline H87Q & $\begin{array}{l}\text { Naturally occurring polymorphism } \\
\text { Reduced CypA binding } \\
\text { Renders HIV-1 independent from CypA } \\
\text { MX2 resistance }\end{array}$ & Cyclophilin A binding loop & [113] \\
\hline G89V & $\begin{array}{l}\text { Loss of CypA binding } \\
\text { MX2 resistance } \\
\text { Higher sensitivity to IFN-a }\end{array}$ & Cyclophilin A binding loop & [113] \\
\hline P90A & $\begin{array}{l}\text { Loss of CypA binding } \\
\text { Higher sensitivity to human TRIM5a } \\
\text { MX2 resistance } \\
\text { Stimulates type I IFN response in primary macrophages }\end{array}$ & Cyclophilin A binding loop & [110] \\
\hline A92E & $\begin{array}{l}\text { CsA dependency } \\
\text { Cell cycle dependency }\end{array}$ & Cyclophilin A binding loop & [140] \\
\hline G94D & $\begin{array}{l}\text { CsA dependency } \\
\text { Cell cycle dependency }\end{array}$ & Cyclophilin A binding loop & {$[140]$} \\
\hline G116A & $\begin{array}{l}\text { Naturally occurring polymorphism } \\
\text { Increases infectivity in simian cells } \\
\text { MX2 resistance }\end{array}$ & Helix 6 & {$[240]$} \\
\hline R132K/L136M & $\begin{array}{l}\text { CTL escape mutations } \\
\text { CSA dependency } \\
\text { Cell cycle dependency }\end{array}$ & Helix 7 & {$[146]$} \\
\hline R143A & $\begin{array}{l}\text { Resistance to TRIM-NUP153 } \\
\text { Unable to stimulate cGAS-dependent innate immune activation in } \\
\text { THP-1 cells }\end{array}$ & Helix 7 & {$[22,61]$} \\
\hline $\mathrm{K} 182 \mathrm{R}$ & Reduced CPSF6 binding & Helix 9 & {$[188,189]$} \\
\hline Q219A & $\begin{array}{l}\text { Hypostable core } \\
\text { Cell cycle dependency }\end{array}$ & Helix 11 & {$[22,61]$} \\
\hline
\end{tabular}

This review article provides an overview of the phenotypic consequences of sequence variation in CA. Naturally occurring polymorphisms and lab-derived mutations are two major sources of CA sequence variation (summarized in Table 1; Fig. 1). We will focus on the results from recent literature exploring CA sequence variations that modulate HIV-1 binding to capsid-binding molecules and ultimately affect phenotypic properties of HIV-1 (Table 2). Lessons learned from these studies illuminate how capsid interactions 

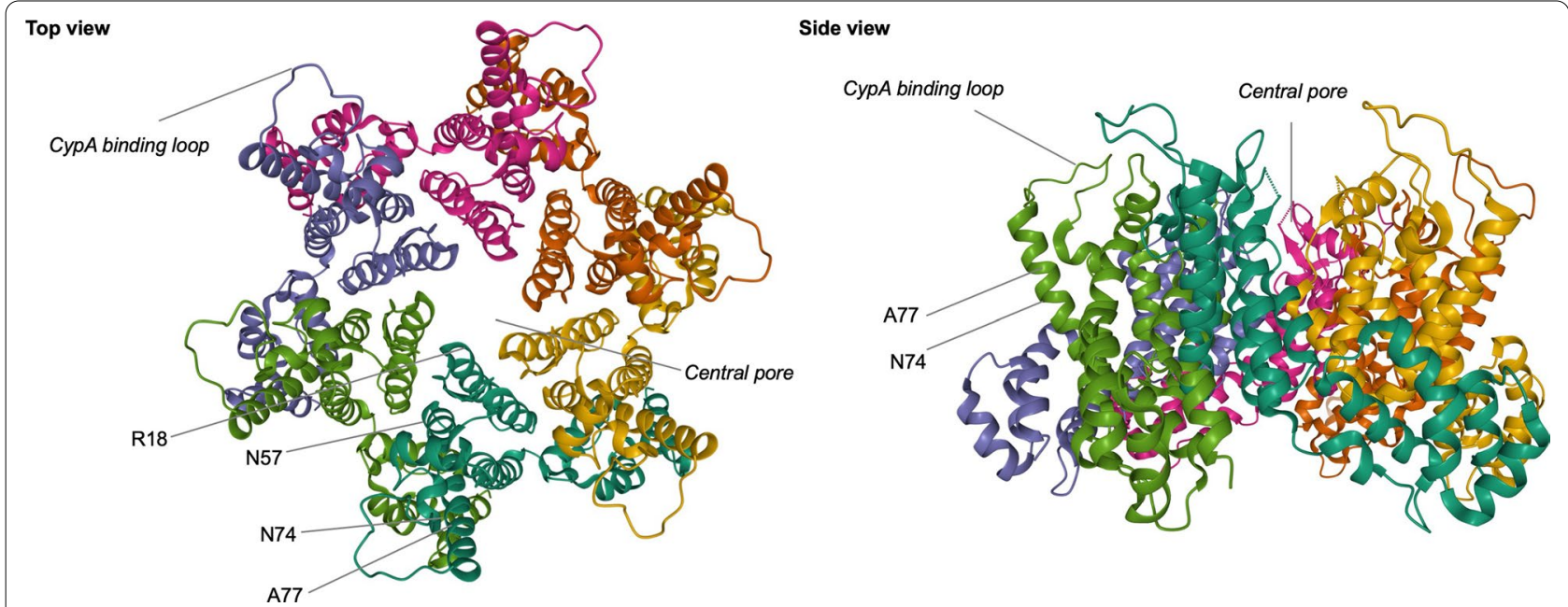

Fig. 1 Host factor interaction sites in the HIV-1 CA hexamer. Structure of an HIV-1 CA hexamer (PDB: 4XFY) is shown in a top (left) or side view (right) with each protomer depicted in a different color. Amino acid residues or regions that mediate interactions with major host factors are indicated

Table 2 Capsid-dependent cellular proteins

\begin{tabular}{|c|c|c|c|c|c|}
\hline Gene name & Gene ID & Also known as & Gene description & Strategy for gene discovery & References \\
\hline CPSF6 & 11052 & $\begin{array}{l}\text { Cleavage and polyadenylation } \\
\text { specific factor } 6\end{array}$ & $\begin{array}{l}\text { Subunit of a cleavage factor } \\
\text { required for } 3^{\prime} \text { RNA cleavage and } \\
\text { polyadenylation processing }\end{array}$ & Expression cloning & [93] \\
\hline Cyclophilin A & 5478 & PPIA & $\begin{array}{l}\text { Member of the peptidyl-prolyl cis- } \\
\text { trans isomerase (PPlase) family }\end{array}$ & GAL4 two-hybrid screen & {$[104]$} \\
\hline FEZ1 & 9638 & $\begin{array}{l}\text { Fasciculat ion and elongation } \\
\text { protein zeta } 1\end{array}$ & $\begin{array}{l}\text { Ortholog of the Caenorhabditis } \\
\text { elegans unc- } 76 \text { gene that is } \\
\text { necessary for axonal bundling and } \\
\text { elongation within axon bundles }\end{array}$ & RNAi-mediated inhibition & {$[100]$} \\
\hline KIF5B & 3799 & Kinesin family member $5 b$ & $\begin{array}{l}\text { Member of the kinesin family } \\
\text { protein with ATPase that acts as a } \\
\text { microtubule motor }\end{array}$ & $\begin{array}{l}\text { Pharmacological and RNAi-medi- } \\
\text { ated inhibition }\end{array}$ & [125] \\
\hline$M \times 2$ & 4600 & MXB, MX dynamin like GTPase & $\begin{array}{l}\text { Member of both the dynamin fam- } \\
\text { ily and the family of large GTPases }\end{array}$ & Transcriptional profiling & {$[156,292,293]$} \\
\hline NUP153 & 9972 & Nucleoporin 153 & $\begin{array}{l}\text { Nucleoporin carrying characteristic } \\
\text { XFXFG pentapeptides }\end{array}$ & Large-scale RNAi screening & {$[356,357]$} \\
\hline NUP358 & 5903 & RANBP2 & $\begin{array}{l}\text { A large RAN-binding protein } \\
\text { that localizes to the nuclear pore } \\
\text { complex }\end{array}$ & Large-scale RNAi screening & {$[356,357]$} \\
\hline SUN2 & 25777 & $\begin{array}{l}\text { Sad1 and unc } 84 \text { domain contain- } \\
\text { ing } 2\end{array}$ & $\begin{array}{l}\text { An inner nuclear membrane pro- } \\
\text { tein with a major role in nuclear- } \\
\text { cytoplasmic connection }\end{array}$ & Sun2-null mouse cells & {$[129,358]$} \\
\hline TNPO3 & 23534 & Transportin (TRN) 3/TRN-SR2 & $\begin{array}{l}\text { Nuclear transport receptor for } \\
\text { serine/arginine-rich proteins }\end{array}$ & $\begin{array}{l}\text { Yeast-two-hybrid and siRNA } \\
\text { screens }\end{array}$ & {$[356,357,359]$} \\
\hline TRIM5a & 85363 & Tripartite motif containing $5 a$ & $\begin{array}{l}\text { Member of the tripartite motif } \\
\text { (TRIM) family }\end{array}$ & Expression cloning & [230] \\
\hline TRIM34 & 53840 & Tripartite motif containing 34 & Member of the TRIM family & HIV-CRISPR screening & {$[290]$} \\
\hline
\end{tabular}

with host factors shape HIV-1 biology, and also have implications for the evolutionary potential of the HIV-1 capsid, a property that is imperative to the emergence of drug resistance. 


\section{Assembly and maturation}

Virion morphogenesis, a key process for HIV-1 replication, depends on the proper assembly and maturation of virus particles [3, 14, 15]. Mutagenesis studies showed that many amino acid changes in the CA domain of Gag block infectious virus production. Some mutations in CA inhibit release of virus particles, while other mutations produce particles that are not infectious. Viral assembly and maturation processes are blocked by perturbation of either CA-CA interactions or CA interactions with host factors.

\section{Immature particle assembly}

The CA domain of Gag facilitates the formation of immature virus particles by providing critical protein-protein contacts for Gag multimerization [16, 17]. Unbiased and structure-guided mutagenesis studies carried out in the past identified a multitude of CA mutants that are blocked at virus assembly [18-24]. The vast majority of these mutations reside in interfaces in the CA domain that participate in Gag multimerization [3, 15]. The CA C-terminal domain (CTD) contains three well characterized sequence elements that promote Gag assembly. Dimeric interactions of CA subunits between neighboring hexamers are mediated by interfaces containing two hydrophobic residues (W184 and M185) in the helix 9 of CA $[22,25]$. The carboxy-terminal end of CA and beginning of the SP1 region forms a six-helix bundle to promote Gag multimerization [26-30]. A third sequence element is the major homology region (MHR), a stretch of 20 amino acids highly conserved among diverse retroviruses, which is important for Gag hexamerization [3135]. The CA N-terminal domain (NTD) also participates in Gag-Gag interactions [22, 36].

A major phenotypic change caused by many CA mutations at the interfaces critical for Gag multimerization is the reduction in particle production and release, which are assessed by measuring the quantity of Gag released in the supernatant or that of reverse transcriptase incorporated into particles. Several CA mutations were shown to prevent the formation of an immature structure using in vitro assembly assays [37, 38]. Additionally, some mutants defective for virus production impair Gag multimerization [39]. For instance, viruses carrying single mutations at the C-terminus of CA-CTD fail to form large Gag complexes as efficiently as the WT virus [28, 30]. Using centrifugation-based assays that can assess biophysical characteristics of assembly intermediates, different CA mutants were shown to be arrested at different stages during the assembly process in virus-producing cells $[35,40]$.

Interactions of the $\mathrm{CA}$ domain with host factors are also critical for immature particle assembly [41]. One such factor that has recently received considerable attention is inositol hexakisphosphate (IP6), which is a negatively charged metabolite [38, 42-44]. HIV-1 binding to IP6 during virus assembly is mediated by two positively charged lysine rings (K158 and K227 in CA amino acid numbering) located in the CA-CTD [45]. Amino acid substitutions at these two positions, such as K158A/I and K227A/I, impair viral infectivity by reducing particle production [45-48].

The requirement of IP6 for immature virus assembly has been studied for other lentiviruses. The two key lysine residues (K158 and K227) are both conserved in CA sequences from diverse lentiviruses. Production of distantly related HIV-1 Group O, HIV-2, and simian immunodeficiency virus (SIV) was reduced when IP6 was depleted by gene knockout of the inositol-polyphosphate multikinase (IPMK) gene or the inositol-pentakisphosphate 2-kinase (IPPK) gene, which regulates IP6 synthesis [46, 49]. In contrast, the dependence of non-primate lentiviruses on IP6 appears to be different. Knockout of the IPMK or IPPK gene reduced production of ferine immunodeficiency virus (FIV) particles [46]. Another study also showed a threefold reduction in production of FIV and equine infectious anemia virus (EIAV) in IPPK-deleted cells; however, re-introduction of IPPK did not affect virus production of both FIV and EIAV [49]. Additionally, both EIAV and FIV required a larger amount of IP6 than HIV-1 in in vitro Gag assembly assays [50]. Based on these observations, Ricana et al. have suggested that IP6 is required by primate lentiviruses for virion production and acts as an enhancer to virus particle release of non-primate lentiviruses [49].

\section{Mature capsid formation}

Mature capsid formation is essential for production of infectious virus particles [16, 17]. Many CA mutants are capable of releasing virus particles, but display a lethal phenotype caused by a defect in the maturation process. During maturation, CA subunits liberated from the precursor Gag protein assemble to form mature cores that are competent for all the post-entry processes [51, 52]. The formation of mature cores is dependent on multiple CA-CA contacts, including intra-hexameric NTD-NTD and NTD-CTD contacts as well as CTD-CTD interactions that connect adjacent hexamers or pentamers [52]. A large number of mutations in these CA-CA interaction interfaces block mature capsid formation [22, 24, 53-58]. Many, but not all, CA mutants that are defective in maturation display aberrant core morphology; some particles lack a defined core, while others contain anomalously shaped cores $[21,22,54-56,59]$. 
In some instances, HIV-1 CA mutants are capable of producing regular conical cores, which display size distributions similar to those of the WT virus, but their infectivity is severely impaired. One common mechanism of such phenotype is that CA mutations alter capsid stability. The requirement of optimal capsid stability has been demonstrated for replication of HIV-1, SIV, and Rous sarcoma virus (RSV) [55, 59-65]. Capsid stability and its effect on capsid disassembly have been studied in cellfree and cell-based assays, which will be described below.

A well-used cell-free experimental approach to measure capsid stability depends on biochemical assays in which viral cores are physically separated from detergent-treated virus particles using ultracentrifugation [61]. Core yield is frequently used as an indicator of capsid stability. This approach has been complemented by cellfree imaging assays [66-68]. In these microscopy-based assays, virus particles on the slide are permeabilized to promote the release of CA subunits before measuring the amount of CA that remains associated with virus particles. In this type of imaging assays, a virus carrying an E45A substitution, which is one of the first identified mutations that increase capsid stability, displayed a slower kinetics of CA release, whereas CA signals were quickly lost from virus particles of the hypostable K203A mutant [66-68]. These observations are consistent with those from the biochemical approach [61].

A group of capsid stability mutants described by Forshey et al. [22, 61] have been examined by multiple laboratories using a variety of cell-based assays to understand how intrinsic capsid stability influences capsid disassembly in virus-infected cells. There are generally three approaches to study capsid disassembly in cells [8]. Imaging assays visualize intracellular complexes and assess the state of uncoating by monitoring different readouts, such as CA molecules associated with cores, viral RNA exposure, and leakage of fluid markers [69-74]. Another approach involves the isolation of subviral complexes from virus-infected cells and their biophysical and biochemical characterization [75-77]. Finally, infectivitybased assays take advantage of a unique property of TRIM5 proteins, such as TRIM5 $\alpha$ and TRIMCyp [78, 79]. The premise of TRIM5-based assays is that TRIM5 proteins only recognize the intact capsid and hence inhibit infection of viral particles that remain "coated". In the cyclosporine A (CsA) washout assay, the drug CsA can be utilized as an off switch for TRIMCyp restriction by preventing its interaction with the viral capsid. A similar infectivity-based assay depends on the fact that virus-like particles, when added in trans, can saturate restriction of HIV-1 by TRIM5 proteins [78].

Overall, the results obtained with these assays showed that capsid stability mutations drastically alter the intracellular behavior of HIV-1 particles. In addition, intrinsic capsid stability generally correlates with intracellular capsid disassembly, albeit with a few exceptions. E45A and E128A/R132A mutations generate hyperstable cores [61] and delay the kinetics of capsid disassembly in cells $[66,71,78,80-85]$. On the other hand, K203A and Q219A mutations destabilize cores [61], and the capsid disassembly of these mutants in target cells is accelerated $[66,69,71,83,85,86]$. The P38A mutant is another example of the mutants with unstable cores [61]. The P38A mutant failed to enhance infectivity of reporter virus as efficiently as WT particles in TRIM5-based abrogation experiments $[86,87]$, while the same P38A substitution led to the loss of $\mathrm{CA}$ and the viral integrase protein in core-containing fractions in a fate-of-capsid assay [85].

On the contrary, more complicating phenotypes were observed for other mutants that moderately reduce capsid stability. The Q63A/Q67A mutant has unstable cores and uncoats faster than the WT virus in a cell-free assay [61]. However, in cell-based assays, Q63A/Q67A cores disassemble at a slower kinetics than WT cores [69, 81, 88, 89]. An R143A mutation displays varying phenotypes across different assays. In a cell-free assay, the R143A mutation decreased the core yield, but paradoxically it delayed the uncoating kinetics [61]. The R143A phenotype was equally variable in cell-based uncoating assay where the R143A mutant showed accelerated or delayed uncoating phenotypes, depending on the assays employed $[69,78,90]$. The discrepancy between cell-free and cell-based assays may be explained by effects of cellular factors on capsid disassembly in target cells. It is unclear what variables underlie the opposing phenotypes of the R143A mutant in different cell-based assays for capsid uncoating.

Capsid stability mutants vary in other post-entry processes. A block in infection of most of these mutants occurs at reverse transcription, regardless of the type of changes in capsid stability $[21,54,56,61,91]$. In contrast, a capsid stability mutant, Q63A/Q67A, is competent for reverse transcription, pointing to a block at nuclear entry [88]. In fact, several studies showed evidence for unusual phenotypes in nuclear entry caused by altered capsid stability. For instance, E128A/R132A and K203A mutants block nuclear envelope association and nuclear transport of pre-integration complexes (PICs) labeled with the APOBEC3F-YFP marker [70, 92]. Elevated accumulation of viral cores in the cytoplasm was observed for the hyperstable E45A mutant [83]. Furthermore, infection by many of these capsid stability mutants does not depend on nuclear entry cofactors exploited by many HIV-1 strains. E45A, P38A and Q63A/Q67A mutants were partially or completely insensitive to NUP153 knockdown [93-95]. 
IP6, a critical factor for immature particle assembly (see above), has been implicated in capsid maturation and stability [44, 45, 96-98]. A current model is that IP6 incorporated into HIV-1 particles is liberated after the protease-mediated cleavage of Gag and binds to an electropositive charged pocket created by arginine residues at position 18 (R18) of CA [42, 96, 99]. Interestingly, this pocket appears to be also utilized by the kinesin-1 adaptor protein FEZ1 [100, 101]. Lysine residues at position 25 (K25) were also shown to be involved in the IP6dependent capsid maturation and dNTP import through dynamic capsid pores $[68,99,102]$. Mutations of R18 and K25 have moderate to severe defects in viral infectivity, which are accompanied by a reduced level of reverse transcription products [24, 42, 99]. IP6 binding differs between these mutants; R18G, but not K25N/A, lost IP6 binding, although both R18 and K25 mutants became insensitive to IP6 in cell-free assays for capsid stability and reverse transcription [99]. Virus particle morphology also differs between these mutants. R18G, K25I and K25N mutants do not alter virion morphology [24, 68]. In contrast, $\mathrm{R} 18 \mathrm{~A}$ is responsible for the altered capsid assembly property by the double mutant R18A/N21A, which forms a variety of abnormally shaped capsids [22, $58,103]$, while most particles of the K25A mutant are defective [99]. However, all these mutants differ from the WT virus in their capsid assembly phenotypes when examined using recombinant proteins in vitro $[42,99]$. Viruses bearing R18 or K25 substitutions display destabilizing effects on HIV-1 cores [61, 68, 99]. This finding fits well with the inability of K25A to abrogate TRIM5 $\alpha$ restriction [99]. Importantly, a similar core-destabilizing effect was observed for K227 mutations, which reduce the amount of IP6 incorporated into virus particles [46]. Diverse lentiviruses contain positively charged amino acid residues (arginine or lysine) at the position corresponding to R18 in HIV-1, whereas the lysine ring does not seem to be conserved across primate and nonprimate lentiviruses. Further work will be needed to understand the requirement of these charged rings for divergent lentiviruses.

\section{Variability in HIV-1 utilization of capsid-dependent host proteins}

The HIV-1 capsid directly interacts with many host proteins to promote post-entry processes. Genetic, biochemical, and structural studies have discovered two major protein interfaces on the HIV-1 capsid. One interface involves CA binding to cyclophilin A (CypA), while the other is important for capsid interactions with multiple host proteins represented by CPSF6 and NUP153 (Fig. 1). Recent work on these capsid-binding host proteins have uncovered how sequence variation in these interfaces affects viral infectivity as well as other phenotypic properties of HIV-1.

\section{CypA and NUP358}

CypA binds to an exposed proline-rich loop between helixes 4 and $5(\mathrm{H} 4 / 5 \mathrm{~L})$ in the CA-NTD [104]. The H4/5L can also interact with the cyclophilin domain of NUP358, a component of the nuclear pore complex (NPC) [105, 106]. Most mutations in the $\mathrm{H} 4 / 5 \mathrm{~L}$ do not affect virus particle production and mature capsid formation [107], although some were shown to affect core maturation [55, 108]. Phenotypic changes caused by amino acid substitutions in the $\mathrm{H} 4 / 5 \mathrm{~L}$ mostly manifest during post-entry processes.

One group of amino acid changes in the H4/5L block CA-CypA binding. Key amino acids that participate in CA binding to CypA are G89 and P90 residues in the H4/5L [109]. This dipeptide motif is highly conserved among HIV-1 strains. Amino acid changes at these positions (e.g., G89A/V, and P90A) as well as those adjacent to this motif can reduce CA-CypA binding and the amount of CypA incorporated in virus particles [110113]. These CypA-binding mutations inhibit viral infection and propagation in multiple cell types $[111,112$, 114-118].

These mutant viruses deficient for CypA binding are blocked at reverse transcription [21, 111, 118-120]. The P90A mutation did not overtly alter the amount of pelletable CA in a fate-of-capsid assay [107]. In contrast, CypA-binding mutants displayed distinct intracellular trafficking patterns; G89V particles traffic in the cytoplasm at a higher rate of speed than WT particles [121], whereas the P90A mutant facilitates faster docking of intracellular particles at the NPC [92], suggesting that CypA slows down PIC nuclear entry. The capsid is a viral determinant for integration targeting [122]. Both G89V and P90A mutations increase the frequency of integration within transcription units [105], but there have been few studies investigating how the altered integration sites by disrupting CA-CypA interactions affect post-integration processes.

HIV-1 exploits cellular proteins to promote its nuclear entry [6, 123]. A major consequence of disruption of CA-CypA interactions is the change in HIV-1 utilization of nuclear entry cofactors $[94,105]$. NUP358 is a RANbinding cellular protein localized to the cytoplasmic side of NPCs and processes a domain that is homologous to CypA and capable of interacting with incoming capsids $[105,106]$. G89V and P90A substitutions render HIV-1 less sensitive to NUP358 depletion [94, 105, 124]. Additionally, HIV-1 infection causes localization of NUP358 into the cytoplasm, but this phenotype is abolished when incoming virus harbor the P90A change 
[125]. While these reports provided support for the role of the cyclophilin domain of NUP358 for HIV-1 nuclear entry, one report showed that it can be dispensable in certain contexts [126]. NUP153 is another major host protein involved in HIV-1 nuclear entry. CypA-binding mutants became insensitive to NUP153 depletion [94, $95,124]$. A recent report showed that transportin-1 (TRN-1), a transporting receptor, is required for HIV-1 infection. Interestingly, the $\mathrm{G} 89 \mathrm{~V}$ mutation, but not the P90A mutation, decreased TRN-1 dependence of HIV-1 infection [127]. TRN-1 alters the tube structure generated by recombinant CA-NC proteins for the WT virus but not the G89V mutant, suggesting direct CA binding to TRN-1 mediated by the G89 residue [127].

CypA-binding mutations also modulate the sensitivity of HIV-1 to host antiviral proteins. Two well-studied groups of such restriction factors are TRIM5 $\alpha$ and MX2. In general, previous studies demonstrated that CypAbinding mutant viruses are less sensitive to these antiviral proteins (discussed below). There are other host proteins that can block HIV-1 in a manner dependent on the H4/5L. SUN1 is a nuclear membrane protein of which ectopic expression blocks infection of the WT virus, but not the G89V mutant [128]. Additionally, an HIV-2 variant to enhance CA binding to CypA is blocked by a mechanism involving SUN2 [129]. Daxx is another example. The Daxx protein can block HIV-1 infection at reverse transcription [130] but displays differences in antiviral activity between WT and P90A viruses [131]. Proteomic work showed that HIV-1 cores are part of the multi-protein complex composed of Daxx, TNPO3, TNPO1, TRIM5 $\alpha$ and TRIM34, but the P90A substitution decreased the level of capsid associations with these host molecules [131].

Another phenotype altered by these CypA binding mutations is innate sensing of HIV-1. Previous reports suggested that the HIV-1 capsid protects newly synthesized DNA from recognition by host DNA sensors, such as cGAS [132, 133]. Experimental evidence suggested a link that connects CypA-CA interactions with cGASdependent sensing of HIV-1 DNA. Namely, both G89V and P90A mutants were shown to induce an elevated level of type I interferons (IFNs) in macrophages [133136]. Similarly, an HIV-2 variant engineered to enhance its CypA binding ability activates innate immune sensing by cGAS [132]. It was also reported that HIV-1 infection of dendritic cells using Vpx to relieve SamHD1 restriction resulted in the maturation of dendritic cells but the G89V mutation eliminated this immunostimulatory ability [137].

Amino acid changes in the $\mathrm{H} 4 / 5 \mathrm{~L}$ also modulate the sensitivity to antiviral activity mediated by type I IFN activation in target cells. The P90A mutant was more sensitive to IFN- $\alpha$-induced blocks in THP-1 cells [138]. Additionally, an HIV-1 variant carrying multiple substitutions in the H4/5L displayed enhanced IFN- $\beta$ sensitivity in T cells [139]. Both viruses are deficient for CypA binding, but the lack of CypA binding may not be the mechanism of the increased sensitivity to IFN-mediated inhibition, as HIV-1 was able to acquire resistant to IFN$\beta$-mediated restriction without restoring the binding ability to CypA [139].

Another group of amino acid changes in the $\mathrm{H} 4 / 5 \mathrm{~L}$, which are represented by A92E and G94D, cause a phenotype distinct from those by CypA binding mutations. A92E and G94D mutations emerged after HIV-1 replication in the presence of an analog of CsA, which block CA-CypA interactions [140]. These mutant viruses became not only resistant to CsA but also dependent on CsA for efficient replication. Another key characteristic of these CsA-dependent mutants is their reduced ability to infect non-dividing cells [141-143]. The CsA-resistant/ dependent phenotype can be conferred by amino acid changes outside of the H4/5L (e.g., T54A) [141, 142, 144, $145]$, and is also observed in primary isolates [146-149].

The CsA dependence of these mutants appears to be caused by an inhibitory effect of CypA-CA interactions, since other means to disrupt these interactions improve their infectivity [107, 114, 143, 150-153]. However, how these CsA-dependent mutations are blocked by CACypA interactions is somewhat uncertain. Investigation of these CsA-dependent mutants with respect to their reverse transcription, nuclear entry, and capsid disassembly has generated conflicting results between different studies [81, 107, 141-143, 153]. One consistent observation is that infectivity of these mutants is rescued upon CsA treatment several hours after infection [141-143], suggesting that intracellular subviral particles are not immediately destroyed by CypA-mediated restriction.

These mutants are blocked only in certain cell types [107, 114, 143, 150-153]. A model to explain this celltype-dependence is that CsA-dependent mutants are restricted by a host cellular factor [143, 152, 153]. A92E and G94D mutants are not hypersensitive to human TRIM5 $\alpha[154,155]$ and display reduced sensitivity to MX2 [156, 157]. CsA-dependent mutants, including G94D and T54A, can be rescued by mutations (N74D and A105T) that prevent CA binding to CPSF6 [144, 149, $158,159]$, suggesting that endogenous CPSF6 can act as an antiviral molecule against CsA-dependent mutants. Infectivity of CsA-dependent mutants is restored by RNAi-mediated depletion of CPSF6 in one study [149] but not in another study [124]. Additionally, there was no difference in CPSF6 levels between permissive and nonpermissive cells [160]. 
The H4/5L is polymorphic among clinical HIV-1 variants, harboring naturally occurring substitutions, such as H87Q, I91V, and M96I. The H87Q substitution often arises among HIV-1 variants resistant to antiretroviral therapy during the late stage of viral infection [161] or in CTL escape mutants from patients carrying HLA B57 alleles [162]. Viruses carrying these amino acid changes replicate at levels comparable to representative lab-adapted strains. Interestingly, in a head-to-head competition, H87Q became dominant after viral replication in peripheral blood leukocytes [163]. Some, but not all, changes reduce CA binding to CypA; the $\mathrm{H} 87 \mathrm{Q}$ mutation reduces CA-CypA binding by fivefold, whereas the I91V mutation causes a negligible change [113]. Importantly, these amino acid changes can relieve CypA dependence of HIV-1 replication [147, 164-167]. The CypA independence of HIV-1 infection was observed in $15 \%$ of HIV-1 clinical strains [166].

How these naturally occurring polymorphisms in the $\mathrm{H} 4 / 5 \mathrm{~L}$ affect biological properties of HIV-1 has been begun to be investigated. Three amino acid changes (H87Q, A88P, and I91V) were shown to increase capsid stability in the fate-of-capsid assay [135]. Alterations in capsid stability can result in differential innate immune responses in myeloid cells [90, 168, 169]; however, these naturally occurring changes did not lead to an elevated level of IFN induction in macrophages [135]. The primary strain 93BR020 differs from the prototypic HIV-1 strain in four amino acid residues (V86T/H87Q/A92P/ M96I) but is identical to the WT virus in their ability to bind to CPSF6 and utilize NUP358 [170].

Comparative studies of phylogenetically diverse groups of lentiviruses have revealed a complex interplay between CypA and CA during lentiviral evolution. Differences in HIV-1 utilization of CypA are illustrated by HIV-1 Group O, a group of variants phylogenetically distinct from major HIV-1 variants (called Group M) $[171,172]$. Some Group O isolates are resistant to drugs that block CA-CypA interactions [166, 167, 173]. Furthermore, the CypA-binding loop of Group O confers the CsA-resistance/dependent phenotype [150]. The CypA-binding loop of a Group O isolate reduces CypA binding affinity [113]. Another study showed that a region outside of the $\mathrm{H} 4 / 5 \mathrm{~L}$ contributes to the distinct CypA requirement by HIV-1 group O isolates [172].

HIV-2 is distinct from both groups of HIV-1 in its dependence on CypA for infection. HIV-2 does not incorporate CypA or incorporate it at a reduced level in virions when compared to HIV-1 [110, 171]. Similar to HIV-1 group O variants, HIV-2 is insensitive to CypA inhibitors and replicates efficiently in cells deleted of CypA [115, 173-175]. A genetic determinant is the CypA-binding loop, since its transfer to HIV-1 reduces
CA interactions to CypA and also relieves the dependence of HIV-1 infection on CypA [173]. However, a subset of primary HIV-2 variants display an infectivity defect in CypA-deficient cells [176], suggesting that CypA utilization varies between HIV-2 variants.

CypA utilization is not a conserved property of lentiviruses but also not a trait specific for HIV-1. Early studies showed that the Gag protein from certain SIV strains do not bind to CypA [104]. Consistently, viruses that belong to the SIVsmm/mac lineage as well as two strains of SIV from African green monkeys do not package CypA in virus particles $[110,171,177,178]$. These SIV strains replicate in a CypA-independent manner [115, 166, 171]. On the other hand, genetic and biochemical evidence showed the ability of capsids from a variety of lentiviruses to physically interact with CypA, including FIV, SIVcpz, SIVagmTan, SIVgsn, and SIVmnd1 [155, 179-183]. However, their CypA dependence for infection may differ from HIV-1, as some of these viruses appear to be insensitive to inhibitory effects of CsA or related compounds $[166,184]$. The difference between HIV-1 and other CypA-binding viruses is also observed for NUP358 utilization; FIV binds to both CypA and the CypA domain of NUP358, but is resistant to NUP358 depletion $[126,185]$. Additionally, the cyclophilin domain of NUP358 differs in protein sequence between primates. Such differences also lead to differential interactions between NUP358 and different lentiviral capsids, which were proposed to be a mechanism to drive HIV/SIV evolution during cross-species transmission [186].

\section{CPSF6 and NUPs}

CPSF6 is another capsid-binding protein that regulates post-entry processes [93]. CPSF6 binds to a preformed pocket generated by the NTD-CTD interface with a higher affinity to a multimerized form of CA than CA monomers [187-189]. Interestingly, HIV-1 uses this binding pocket to interact with other proteins, such as NUP153 and Sec24C [95, 188-190]. Amino acid substitutions in this CPSF6-binding pocket alter a wide variety of phenotypic properties of HIV-1 and are instrumental in understanding how HIV-1 subviral complexes traverse an intracellular environment to complete the infection process by inserting proviral DNA into the host chromatin.

A broad range of phenotypic outcomes caused by mutations in the CPSF6 binding pocket is illustrated by an N74D substitution, which was originally identified after HIV-1 passage in cells expressing a truncated form of CPSF6 (CPSF6-358) [93]. The side chain of N74 forms a hydrogen bond with CPSF6 [187-189]. The N74D mutation confers resistance to antiviral activity of CPSF6-358 [93, 187, 191] and blocks capsid binding to CPSF6 [93, 187, 192]. Imaging work showed colocalization of HIV-1 
with CPSF6 but this was prevented by the N74D mutation $[121,193,194]$.

The N74D mutant has garnered a great deal of attention, since its infection is independent from HIV-1 nuclear entry co-factors utilized by the WT virus. Namely, infection of the N74D mutant is insensitive to depletion of NUP358 and NUP153 [93, 94, 105]. Additionally, the N74D change alters virus utilization of a comprehensive panel of nucleoporins and nuclear entry cofactors [124, 195, 196]. NUP153 binds to the capsid at the same interface as CPSF6 $[95,188,189]$. However, NUP153 binding is not correlated with NUP153 dependence for infection, as the N74D mutant, which is independent from NUP153, displays hyper-binding activity to NUP153 [95, 197]. The N74D virus maintains the ability to infect non-dividing cells $[93,95,124,197]$. This observation suggests that PICs need to translocate through nuclear pores, and points to a flexibility in how HIV-1 subviral complexes gain access inside the nucleus [93].

Mutant virus bearing the N74D substitution infects immortalized cells without any overt defect [93, 187]. In contrast, the N74D mutant is impaired in primary $\mathrm{CD} 4+\mathrm{T}$ cells and macrophages with decreased levels of revere transcription products and 2-LTR circle formation [133, 159, 198-201]. Interestingly, replication of HIV-1 containing the N74D mutation in macrophages is partially restored by treatment of antibody to the IFN $\alpha / \beta$ receptor $\alpha$ chain as well as capsid-binding small-molecule inhibitors PF74 and BI-2 [133, 198]. HIV-1 infection of macrophages with the N74D mutant was reported to stimulate type I IFN induction [133, 135]. In other studies, the N74D virus did not enhance innate immune responses when used to infect macrophages and CD4 $+\mathrm{T}$ cells $[199,202]$.

The intracellular behavior of the N74D virus has been extensively studied using various experimental approaches. While minor differences exist between studies, a number of distinct phenotypic changes caused by the N74D mutation have been consistently observed across multiple studies. The N74D mutant differs from the WT virus in intracellular trafficking and capsid disassembly. For instance, N74D particles display faster cytoplasm trafficking than WT particles in macrophages [121] and uncoat at the nuclear envelope [83, 194]. The exact timing of HIV-1 uncoating is still a matter of debate [71, 73, 83, 194, 203-208]. However, the N74D mutant, when compared to the WT virus, appears to delay capsid uncoating in various assays [73, 81, 83, 84]. Imaging and biochemical studies showed that fewer numbers of PICs or CA reside in the nucleus for the N74D mutant than the WT virus $[206,209,210]$. The N74D mutant virus also differs from the WT virus in nuclear localization. Subviral complexes of viruses carrying a mutation of
N74 (N74A or N74D) reside near the nuclear periphery or lamina $[83,209]$. Consistent with these findings, transcription sites of the N74D virus are closer to the nuclear envelope than those of the WT virus [194].

CPSF6 plays a key role in directing HIV-1 integration sites toward active chromatin [211], including genes linked to speckle associated domains [212, 213]. This unique integration targeting is abolished by the N74D mutation [105, 197, 199, 211, 214]. How such integration site change alters the level or dynamics of HIV-1 transcription remains unclear. Sadowski et al. used dual reporter virus to find that the N74D virus is the same as the WT virus with respect to the proportion of productive cells, which are active in LTR-driven viral gene expression [215].

The N74D change modulates capsid interactions with other host factors as well. Recent work discovered that Sec24c is a novel capsid interacting protein that promotes early HIV-1 infection [190]. Remarkably, Sec24c binds CA at the binding interface utilized by CPSF6 and NUP153 [190]. The N74D mutation impedes CA binding to the FG motif of Sec24C and is insensitive to Sec24c depletion [190]. The N74D mutation prevents cytoplasmic localization of NUP358 and relieves the requirement of KIF5B for HIV-1 infection [125]. Capsid interactions with CPSF6 also regulate CypA utilization by HIV-1 during post-entry processes, as the N74D mutation was shown to increase the dependence of HIV-1 infection on CypA [159].

Another well studied mutation in the CPSF6 binding pocket is an A77V substitution. The A77V mutation is the HIV-1 counterpart of an A76V replacement in SIVmac CA, which arose after adaption of a chimeric HIV-1 carrying SIVmac CA [216]. The A76V mutation in SIVmac and the A77V mutation in HIV-1 confer resistance to inhibition by CPSF6-358 [199, 360]. The A77V mutation reduces CA binding to CPSF6 [199]. The A77V virus shares many similarities with the N74D virus. Some common properties between these CPSF6-binding mutants include their altered dependence on nuclear entry factors, uncoating at the nuclear envelope and changes in integration targeting [194, 199, 201, 212, 213, 217].

A key difference from the prototypic N74D mutation is that the A77V mutant virus retains a nearly WT-level of infectivity in primary cells $[199,201,218]$. This difference between these two mutants may be explained by differential sensitivity to TRIM34, which blocks the N74D virus, but not the A77V virus [219]. The A77V virus replicated in humanized mouse as efficiently as the WT virus [199]. However, the A77V CA reverted back to the WT CA in multiple animals [199]. These observations suggest that optimal CPSF6 binding to the viral capsid is not an absolute requirement for HIV-1 replication but confers 
a moderate but significant fitness advantage to CPSF6binding viruses.

The A77V mutation has been used a tool for cell-based imaging studies of CPSF6 functions in primary cells, which substantiated earlier observations made with the N74D mutation in immortalized cells. For instance, A77V subviral complexes accumulate at the nuclear envelope and are associated with NPCs [201]. Additionally, A77V infection resulted in a reduced number of HIV-1 subviral complexes in the nucleus detected by CA and viral DNA signals [201]. Zila et al. leveraged the ability of the A77V mutation to increase the steady-state accumulation of virus complexes at nuclear pores to visualize cone-shaped capsids inside the NPC central channel and their morphological alterations [208].

The N57 residue in the helix 3 is a key amino acid residue involved in capsid binding to CPSF6 and other host factors $[95,187,188]$, and its mutations change several phenotypic characteristics differently from both N74D and A77V mutations. The N57A substitution abrogates CA binding to CPSF6 and renders HIV-1 insensitive to CPSF6-358 [95, 187, 191, 197]. Similar to other CPSF6 binding mutations, the N57A mutation also blocks CA binding to Sec24c [190]. The N57A mutation alters nuclear entry and integration targeting $[105,197]$. The N57A mutant also resembles the N74D mutant in that their infectivity defect is exacerbated in the presence of CsA [105], suggesting a link between CypA and CPSF6 binding to $\mathrm{CA}$. In vitro evolution of virus harboring the N57A substitution resulted in selection for a compensatory mutation of G94D in the CypA-binding loop [220]. Importantly, the G94D variant by itself is also rescued by the N74D substitution [159], underscoring similarities between N57A and N74D mutations.

A key difference between positions 57 and 74 is their mutational effects on CA binding to nucleoporins. N57 mutations (N57A/D/S) block CA interactions with NUP153 [95, 197] as well as other nucleoporins including NUP62, NUP98, and NUP214 [197]. Another fundamental difference is that several amino acid changes at position 57 impair the ability of HIV-1 to infect non-dividing cells $[24,89,95,105,197]$. It is possible that N57A's loss of NUP binding may account for the relative lack of these mutants to infect cells independent from cell cycle progression [95, 197]. Finally, virus carrying the N57A change is severely defective in primary CD $4+\mathrm{T}$ cells and macrophages $[89,220]$, a property shared by N74D but not A77V mutations. However, unlike the N74D virus, the N57A virus is not restricted by TRIM34 [219].

Other mutations in the CPSF6 binding pocket (M66F, Q67A, K70A, A105S/T, T107A/I, and K182R/A) also affect capsid binding to CPSF6 [138, 149, 187, 188, 191, 199], while amino acid changes outside of this CPSF6 binding pocket were shown to change the sensitivity of HIV-1 to restriction by CPSF6-358 [139, 221]. CPSF6 binding generally correlates with HIV-1 dependence on nuclear entry co-factors, such as NUP358 and NUP153. As such, most of the variants harboring amino acid changes in the CPSF6 binding pocket reduce the sensitivity to depletion of NUP358 and TNPO3 [149, 191, 222]. The A105T mutant was also shown to share a similar nuclear phenotype with the N74D and A77V mutants in that their integration occur at the nuclear periphery [209].

It is notable that amino acid replacements at some of these positions, in particular positions 105 and 107, repeatedly emerged after virus propagation in different contexts. For instance, the A105T change was identified after serial passage of the T54A mutant virus, a CsAresistant/dependent virus [144]. The T107I mutation was identified after in vitro evolution of a CTL escape variant that lost the cell-cycle independence for infection [149]. As we will describe below, other studies identified drug resistant mutations at these positions [223-225]. Thus, these two amino acid residues (A105 and T107) are among those in CA that are most tolerable to mutational changes.

Amino acid residues in the CPSF6 binding pocket are not completely conserved among diverse strains of lentiviruses. Previous work demonstrated that different lentiviruses vary in their utilization of host factors that bind to the CPSF6 binding pocket. HIV-2 and closely related SIVmac are a group of viruses that exploit CPSF6 for viral propagation. CA of HIV-2 and SIVmac was shown to bind to CPSF6 [187]. Key mutations in the CPSF6 binding pocket, such as N56A and N73D (HIV-2/SIVmac numbering), indeed conferred resistant to CPSF6-358 [187]. In contrast, HIV-2 and SIVmac appear to be less dependent on the K182 residue for CPSF6 binding than HIV-1 [226].

In contrast to primate lentiviruses, non-primate lentiviruses, such as bovine immunodeficiency virus (BIV), FIV and EIAV, are resistant to cytoplasmic CPSF6 [93, 227]. Consistently, non-primate lentiviruses did not show a strong preference for speckle associated domains as integration sites [213]. Furthermore, CPSF6 absence did not strongly affect integration targeting of non-primate lentiviruses [213]. Sec24c is nearly identical to CPSF6 in its requirement for infection by diverse lentiviruses, as EIAV and FIV were not affected by Sec24c knockout in contrast to some SIV strains of which infectivity were reduced in cells lacking Sec24c [190].

NUP153 utilization by related lentiviruses exhibits a pattern slightly different from that for CPSF6. SIVmac, SIVagmSab and SIVagmTan are sensitive to inhibition by NUP153 knockdown [95]. However, NUP153 
requirement for infection is not conserved among primate lentiviruses, as the sensitivity of NUP153 depletion drastically vary among circulating SIV strains [184]. Non-primate lentiviruses, FIV and BIV, are resistant to NUP153 knockdown without any binding activity. In contrast, EIAV has an appreciable ability to interact with NUP153 and utilizes it for infection [95]. Interestingly, EIAV CA binds to NUP153 in a manner different from HIV-1 [95]. Overall, EIAV and FIV were shown to be less sensitive to inhibitory effect of depletions of multiple nuclear entry factors $[93,124]$

\section{Capsid-targeting antiviral molecules}

A variety of molecules directly bind to the HIV-1 capsid and block viral infection. These capsid-targeting antiviral molecules can be either host-encoded restriction proteins or small-molecule compounds. Two major groups of capsid-dependent host factors that will be discussed below are TRIM5 and MX2. On the other hand, previous drug development efforts culminated in the discovery of several small-molecule compounds that block capsid-related functions with different mechanisms of action. Extensive research in the past has elucidated how these antiviral molecules recognize the viral capsid and interfere with capsid-mediated processes. Furthermore, comprehensive characterization of escape variants that acquired resistance to these capsid-dependent antiviral molecules has illuminated the viral evasion mechanism and identified sequence elements of CA that are vulnerable to mutational effects and those that possess adaptive potential.

\section{TRIM5}

TRIM5 proteins are capsid-dependent restriction factors and consist of TRIM5 $\alpha$ and TRIMCyp [228-233]. TRIM5 directly binds to the HIV-1 capsid and accelerates uncoating to prevent reverse transcription [75]. TRIM5 $\alpha$, which has evolved under positive selection in primates [234], is a major determinant for species-specificity of retroviruses [235-237]. For instance, human TRIM5 $\alpha$, while ineffective for HIV-1, potently blocks infection by $\mathrm{N}$-tropic murine leukemia virus (N-MLV) or EIAV. In contrast, HIV-1 infection is severely impaired by TRIM $5 \alpha$ from Old World monkeys. Past studies used both in vitro and in vivo model systems to reveal how sequence variation in CA among HIV-1 and other lentiviruses influences the sensitivity to restriction mediated by TRIM 5 proteins.

HIV-1 is blocked by TRIM5 $\alpha$ from many species of Old World monkeys. Previous work frequently relied on restrictive alleles of TRIM $5 \alpha$ from rhesus macaques (RMs) in order to map the viral determinant of HIV-1 restriction by TRIM $5 \alpha$. These studies demonstrated that HIV-1 restriction by TRIM $5 \alpha$ is mediated by multiple interfaces exposed on the external surface of the viral capsid [237, 238].

A flexible loop between $\alpha$-helices 4 and 5 of CA (H4/5L), which binds to CypA, is one major determinant of TRIM $5 \alpha$ restriction of HIV-1 [235, 239]. Replacement of the HIV-1 H4/5L with the corresponding sequence from SIVmac, an RM-derived SIV strain insensitive to restriction by RM TRIM $5 \alpha$, restored HIV-1 infectivity in monkey cells [240, 241]. Single amino acid changes in the H4/5L also enhance HIV-1 infection in cells expressing RM TRIM5 $\alpha$ [240, 242, 243]. One such change, H87Q, is present in circulating HIV-1 strains [161]. Similarly, CA from a certain type of naturally occurring HIV-1 variants enables HIV-1 to evade restriction in simian cells $[164,244]$. The role of the H4/5L in capsid recognition by TRIM $5 \alpha$ was also supported by in vitro HIV-1 evolution under selective pressure from RM TRIM5 $\alpha$ [243, 245, 246]. HIV-1 variants that had adapted to restriction by RM TRIM5 $\alpha$ gained amino acid replacements within the H4/5L (e.g., V86M, H87Q, V86E, I91N, and I91T). The V86M mutation was shown to reduce capsid binding to RM TRIM $5 \alpha$ while maintaining binding with CypA [245]. A TRIM $5 \alpha$-resistant mutation was also found outside of the CypA-binding motif but located within the H4/5 loop (R100S in HIV-1 numbering) [247].

A second region of the capsid surface that confers resistance to TRIM5 $\alpha$ involves helix 6 . This region contains an exposed loop formed by the $\mathrm{C}$-terminal portion of helix 6 and a mini- $\beta$-hairpin that connects helices 6 and 7 [240]. This region also includes a ridge formed at the interface of helices 3 and 6 (helix 3/6 ridge) [242]. Amino acid changes at position 116 enhance HIV-1 infection in RM TRIM5 $\alpha$-expressing cells [240, 243]. One such mutant, G116E, was indeed shown to resist TRIM $5 \alpha$-mediated disruption of HIV-1 cores [243]. Notably, the CA 116th amino acid residue is polymorphic among HIV-1 strains, suggesting that it plays a role during viral adaptation. Interestingly, this position is one of the determinants for MX2 restriction of HIV-1 (discussed below). A Q112D substitution in helix 6 is another mutation that was shown to improve replication of monkey-tropic HIV-1 in simian cells [247, 248]. Additionally, viruses containing various mutations in the helix $3 / 6$ ridge were shown to be more infectious in simian cells [242].

The $\mathrm{N}$-terminus of $\mathrm{CA}$ has a $\beta$-hairpin structure, which is surface exposed and modulates HIV-1 sensitivity to TRIM5 $\alpha$. Amino acid replacements, such as N5D, Q7A/ Q9A, M10I/L/V, M10L, and M10V, conferred partial resistance to RM TRIM5 $\alpha$ [240, 243]. A similar observation was made in work studying the sensitivity of HIV-2 
or SIVmac239 to monkey TRIM5 $\alpha$ [249]. Additional support for the role of this $\beta$-hairpin structure as a recognition motif for TRIM5 $\alpha$ came from work examining the consequence of adaptation of N-MLV to RM TRIM5 $\alpha$ [250]. This work identified several TRIM5 $\alpha$ resistant mutations, which include a L10W change in the $\beta$-hairpin loop. Additionally, gain-of-sensitivity experiments in which a resistant SIVmac strain was engineered to acquire the sensitivity to restriction by RM TRIM5 $\alpha$ suggested that the CPSF6 binding pocket can also influence HIV-1 restriction by TRIM $5 \alpha$ [251].

Overall, these findings suggest that TRIM $5 \alpha$ recognizes multiple epitopes exposed on a large surface of the viral capsid [243, 247, 248, 250-253]. This idea based on mutational studies has been also supported by biochemical and structural studies [254-261]. Notably, these resistant mutations, when individually introduced to HIV-1 CA, only confer partial resistance to RM TRIM $5 \alpha$. Several studies demonstrated that a combination of amino acid changes on the exposed surface are required for rendering HIV-1 fully resistant to RM TRIM $5 \alpha$. Considerable efforts have been made to generate an HIV-1 variant that completely evades restriction by RM TRIM $5 \alpha$ while retaining the full replicative capacity, as such virus would serve as an invaluable tool for improving the macaque model of HIV-1 [262, 263]. Several laboratories harnessed the knowledge obtained from these studies and successfully achieved the goal to engineer the viral capsid that enables HIV-1 variants to efficiently replicate in RM cells [243, 247, 264].

TRIMCyp is a chimeric protein between TRIM5 $\alpha$ and CypA and encoded by certain species of Old World and New World monkeys [232, 233, 265-269]. The CypA domain of TRIMCyp mediates capsid recognition by interacting with the $\mathrm{H} 4 / 5 \mathrm{~L}$ of $\mathrm{CA}$, which contains the CypA-binding motif. As expected from this binding mechanism, individual or a combination of mutations in the H4/5L (e.g., H87Q, and G89V) are able to enable HIV-1 to infect TRIMCyp-expressing cells $[164,165,232$, 233, 270].

Antiviral activity of TRIMCyp varies among different species. Owl monkey TRIMCyp differs from its counterparts from Old World monkeys. For instance, previous studies showed that TRIMCyp in Old World monkeys originated through an independent event of retrotransposition of the CypA sequence in the $3^{\prime}$ untranslated region of the TRIM5 gene [265-269]. Additionally, TRIMCyp from cynomolgus macaque (CM) is polymorphic and this polymorphism affects susceptibility to HIV-1 infection [271-273]. Namely, HIV-1 infection was blocked by CM TRIMCyp carrying aspartic acid (D) and lysine $(\mathrm{K})$ at positions 369 and 446 (denoted as the DK haplotype) [271-273], but not by another haplotype of
CM TRIMCyp carrying asparagine $(\mathrm{N})$ and glutamic acid (E) in corresponding residues (denoted as the NE haplotype) [271-273]. In contrast, HIV-2 can be effectively blocked by TRIMCyp (NE). The differential sensitivity to restriction by TRIMCyp (NE) is governed by the 88th residue of $C A$ [274].

As discussed above, HIV-1 can fully evade TRIMCyp restriction by just a single amino acid substitution. However, an HIV-1 variant that acquired resistance to TRIMCyp presented a more complicated scenario [275]. In this study, a combined approach of random mutagenesis and in vitro adaptation was used to yield an HIV-1 clone with high resistance to CM TRIMCyp [275]. The adapted variant was shown to carry four amino acid changes in the H4/5L (H87R, A88G, P90D, and P93A) in addition to a Q112D change in helix 6 of CA-NTD. Notably, this CA variant is completely resistant to TRIMCyp-mediated restriction, whereas the P90A CA mutant remains partially sensitive to TRIMCyp [139]. Thus, in two studies using similar combinatory approaches to generate HIV-1 variants resistant to RM TRIM5 $\alpha$ or CM TRIMCyp [243, 275], multiple amino acid replacements in HIV-1 CA were required to overcome antiviral activity by these TRIM5 proteins. An additional study showed that this TRIMCyp-resistant variant gained unusually high sensitivity to type I IFNs [139]. It is currently unknown whether the increased sensitivity to type I IFNs is a common property of HIV-1 variants that acquired the resistance to simian TRIM5 proteins.

Studies of cross-species transmissions of African SIV strains to Asian macaques have also revealed how the SIV capsid adapts to the selection pressure imposed by TRIM5 proteins [276]. A well-used model is RM infection with primary or minimally passaged SIV strains from sooty mangabeys (SIVsmm), which are sensitive to restriction by RM TRIM5 $\alpha$ and TRIMCyp. In vivo experiments uncovered a central role of TRIM5 proteins in the susceptibility to SIVsmm infection and the evolution of SIV capsid [277, 278]. Specifically, these studies identified CA mutations that allow escape from viral suppression by TRIM5 proteins [277, 278]. Interestingly, the viral adaptation in this model appears to be achieved through a common evolutionary trajectory; two amino acid substitutions at positions 37 (P37S) and 98 (R98S) were found in multiple animals infected with SIVsmm [277, 278]. Introduction of these two changes together increased SIVsmm infectivity in cells expressing a restrictive haplotype of RM TRIM5 $\alpha$ in vitro [278]. These adapted changes were further validated by in vivo studies in which an SIVsmm variant carrying both P37S and R98S mutations caused higher viremia and lower survival rate than the parental strain in infected animals [279]. Note that the R98S mutation located at the bottom of 
the $\mathrm{H} 4 / 5 \mathrm{~L}$ serves as a primary residue to increase HIV-1 resistance to RM TRIM5 $\alpha$ [247]. In contrast, it is unclear how P37S confers resistance to RM TRIM5 $\alpha$. A possible mechanism is that this mutation may alter capsid stability, since an amino acid change of the corresponding position in HIV-1 reduces capsid stability [61].

Similar studies using the macaque model have yielded new insights into SIVsmm adaption to TRIMCyp. In these studies, the authors found that SIVsmm overcame TRIMCyp restriction by acquiring amino acid changes in the H4/5L (e.g., Q85P, G87Q, L90P, and A92P) [280]. As expected, these mutations rendered the parental SIVsmm strain resistance to RM TRIMCyp. Remarkably, SIVsmm found a way to evade restriction imposed by both TRIM5 $\alpha$ and TRIMCyp; SIVsmm passaged in an animal expressing both TRIM5 $\alpha$ and TRIMCyp accumulated mutations in the $\mathrm{H} 4 / 5 \mathrm{~L}$ as well as the aforementioned P37S and R98S changes. [278]. Many instances of successful adaptation of TRIM5-sensitive SIVsmm to RMs are in stark contrast to the difficulties in enforcing HIV-1 to overcome the species barrier to Asian macaques.

Human TRIM5 $\alpha$ was generally considered to be a weak inhibitor of HIV-1 infection [238]. However, some circulating HIV-1 variants, especially those isolated from protective alleles of HLA, exhibit an elevated level of sensitivity to restriction by human TRIM5 $\alpha[148,281-283]$. HIV-2 is also more sensitive to human TRIM5 $\alpha$ than HIV-1 [176, 284, 285]. Interestingly, a large-cohort analysis in Guinea-Bissau suggested that naturally occurring polymorphisms at position 119 or 120 in CA can influence the viral load in HIV-2-infected individuals [286]. Specifically, CA sequences of HIV-2 from individuals with low viral loads had a proline at position 119 or 120 , whereas those from individuals with high viral loads tended to have non-proline residues [286]. Critically, in vitro studies showed that these positions in HIV-2 CA affect the sensitivity to human and CM TRIM5 $\alpha$ [287, 288], although one study did not find a similar mutational effect when a different CA sequence was used [285].

Recent reports have revealed that human TRIM $5 \alpha$ significantly contributes to IFN-mediated antiviral effects on HIV-1 infection and that CypA protects HIV-1 from TRIM5 $\alpha$ restriction in primary blood cells $[118,120$, 289, 290]. Consistent with these findings, infectivity of CypA-binding deficient mutants, G89V and P90A, was impaired in primary cells but restored by TRIM $5 \alpha$ depletion $[118,120]$. These findings argue that human TRIM5 $\alpha$ is a critical component of the host antiviral system that affects the evolution of the HIV-1 capsid. Consistent with this idea, previous work demonstrated that amino acid replacement with certain low-frequency residues at sites that are under positive selection increased the sensitivity of HIV-1 to human TRIM $5 \alpha$, suggesting that the majority of CA sequences of circulating HIV-1 variants belonging to clade B had optimally adapted to human TRIM5 $\alpha$ [291]. New experimental protocols used in these recent studies $[118,120]$ will be a valuable tool to further study how sequence variation in the $\mathrm{H} 4 / 5 \mathrm{~L}$ and other exposed sequence elements dictates differential sensitivity to human TRIM $5 \alpha$ among different variants of the HIV-1 and HIV-2 lineages.

\section{$\mathrm{MX2}$}

MX2, a member of the dynamin-like GTPase family, is a capsid-dependent HIV-1 restriction factor that is induced upon activation of type I IFN signaling [156, 292, 293]. MX2 is localized to the nuclear envelope and blocks HIV-1 nuclear import [156, 157, 292, 293]. Among several distinct domains of the MX protein, the $\mathrm{N}$-terminal tail is important for localization to the NPC and for antiviral activity [124, 294-298]. MX2 can directly bind to the viral capsid [134, 299-302]. Importantly, the MX2 binding interface of HIV-1 is not present in individual building blocks of HIV-1 capsid, such as CA hexamers, but composed of a structure that is only present in the high-order CA lattice [261, 299-301, 303]. Many amino acid changes that confer MX2 resistance on HIV-1 have been discovered among well-utilized CA mutants, circulating HIV-1 variants and passaged viruses that had been adapted in MX2-expressing cells [156, 157, 292-294, 300]. These MX2-resistance mutations are scattered over the entire sequence of $\mathrm{CA}$, suggesting multiple evasion mechanisms of HIV-1.

A major determinant of MX2 resistance involves the CypA-binding loop. Well-characterized G89V and P90A mutations as well as other amino acid changes (H87R, P90T, and Q95L) in a CA mutant library confer MX2 resistance [134, 156, 157, 292-294, 300, 304]. Virus evolution experiments identified an A88T substitution in the CypA-binding loop, which allows HIV-1 to escape from MX2 restriction [293]. MX2 sensitivity differs among circulating HIV-1 variants and the difference is often determined by naturally occurring polymorphisms in the CypA-binding loop (e.g., V86A/Q, H87P/Q, A88V and A92P) [134, 304]. Many MX2-resistant mutations in the CypA-binding loop diminish CA interactions with CypA. Indeed, MX2 restriction of HIV-1 can be relieved by CsA or CypA depletion [124, 170, 293]. However, CypA-binding mutations did not significantly reduce CA binding to MX2 [299, 300, 303, 304]. Additionally, there is evidence suggesting that CypA recruitment by itself is not essential for the full sensitivity to MX2 restriction [139, 170]. An adapted HIV-1 variant completely lost CypA binding but remained sensitive to MX2 [139]. Likewise, recent work showed that addition of the A92E mutation to the P90A mutant partially rescues MX2 sensitivity 
[170]. As the A92E mutation can reduce the dynamics of the CypA-binding loop [305], a role of the stabilization of the CypA-binding loop was suggested as a mechanism of MX2 restriction of HIV-1 [170].

The CypA binding loop is exposed on the surface of HIV-1 cores. Two other known exposed loops also affect MX2 restriction of HIV-1. Specifically, a mutation in the N-terminal $\beta$-hairpin (M10I mutant) confers resistance to MX2 whereas a Q4R mutation can sensitize MX2 restriction $[139,294]$. The G116 residue in the helix 6 is another residue of which amino acid changes (G116A/ $\mathrm{Q} / \mathrm{R}$ ) diminish MX2 sensitivity of naturally occurring variants [134, 170, 283]. Characterization of a primary strain that is resistant to antiviral activity of MX2 (93BR020) showed that the amino acid at position 116 acts together with a histidine at position 120 and the CypA binding loop to influence MX2 sensitivity of HIV-1 [170].

Another group of MX2 escape mutations are located within the CPSF6 binding pocket, including N57S, K70R, N74D and A105T mutations [134, 156, 157, 292, 300]. A T107I substitution occurred in animal-to-animal passage experiments of a simian-tropic HIV-1 variant and was shown to be linked with MX2 resistance [306]. The T107I mutation reduces CA binding to CPSF6 and impairs virus replication [306]. How CPSF6 binding deficient mutants evade MX2 restriction is unclear. Currently available data do not support strict correlations between MX2 binding and sensitivity; MX2 binding to CA is reduced by N57S, but not by N74D [299, 300]. MX2 restriction of HIV-1 appears to depend on multiple components of host factors required for nuclear entry $[124,196,298]$. However, CPSF6 depletion did not have noticeable effects on MX2 restriction of HIV-1 [124, 170].

The CA-CTD also affects MX2 sensitivity of HIV-1. A CA mutant library was used to identify two MX2-resistant mutations in the CA-CTD (M185I and E187V) [294]. Additionally, escape mutations in the CA-CTD (P207S, G208R, and T210K) arose under pressure from MX2 inhibition during in vitro evolution experiments [294]. Amino acid residues at these three positions are variable among circulating HIV-1 strains. Such naturally occurring variations contribute to differences in MX2 sensitivity. For instance, threonine is frequently found at position 207 among CRF01_AE variants, but replacement of threonine with a more common proline residue increased MX2 sensitivity [307]. Additionally, MX2 resistance of two transmitted founder variants was shown to be determined in part by the G208A substitution [304, 308]. Natural polymorphism at position 210 also affects MX2 sensitivity; viruses bearing a threonine at position 210 are sensitive to MX2 restriction, whereas those with a serine escape from inhibition by MX2 [170]. These mutations are clustered within a trimeric interface in the mature capsid structure. Interestingly, capsid binding to MX2 seems to be the main mechanism for resistance by these CA-CTD mutations. Specifically, both G208R and T210K mutations reduce MX2 binding to CA complexes [303, 309], supporting the idea that the tri-hexamer interface is a key binding site of MX2 [303].

These studies have revealed that HIV-1 can escape from MX2 restriction by multiple mechanisms. Notably, the three exposed sequence elements described above ( $\beta$-hairpin, CypA-binding loop, and helix 6) are known to influence HIV-1 restriction by TRIM $5 \alpha$, suggesting a common recognition mechanism of these two groups of restriction factors [261, 294]. Aside from human MX2, other primate and non-primate species encode MX2 proteins with antiviral activity against HIV-1 [294, 306, 310-312]. Divergent lentiviruses differ widely in their sensitivity to MX2 [124, 156, 157, 292, 294, 300, 311, 313]. Further studies need to be done to fully understand how different capsids adapt to the selection imposed by MX2. It should be also noted that the consequence of MX2 binding to the capsid is likely more complicated than currently appreciated, as it was shown that MX2 can not only block HIV-1 infection but can also enhance it, depending on its CA sequences [124].

\section{HIV-1 capsid inhibitors}

A number of small-molecule compounds that bind the HIV-1 capsid have been developed and explored as a new line of antiviral therapy $[12,13]$. The HIV-1 capsid is an attractive target, as CA plays diverse roles during HIV-1 replication [5] and displays extreme genetic fragility [24]. Previous investigations of capsid-targeting inhibitors have elucidated their binding mode and provided insights into the mechanism of action and drug resistance profile. The best characterized example of capsid inhibitors is PF74, which binds the capsid at a preformed pocket [314]. This PF74 binding pocket is also targeted by other capsid inhibitors, including BI-1 [225], GS-CA1 [315] and GS-6207 [316]. It is worth mentioning that this group of antivirals do exhibit clear differences in mechanisms of action; PF74 and BI-1 mostly target mature particles, whereas GS compounds can act on both immature and mature particles. Below, we will describe recent advances in our understanding of drug resistance mutations in CA and their phenotypic consequences with emphasis on antiviral drugs targeting the CPSF6 binding pockets.

PF74 binds to the viral capsid at a preformed pocket that is composed of the NTD of one CA subunit and the CTD of another in the CA hexamer [188, 189]. As such, PF74 binds to the CA hexamer with higher affinity than to the CA-NTD $[188,189]$. Importantly, PF74 shares its binding site with multiple capsid-binding host proteins, such as CPSF6, NUP153 and Sec24c [95, 187-190]. 
The $\mathrm{EC}_{50}$ of PF74 against HIV-1 $1_{\mathrm{NL} 4-3}$ in MT-2 cells was reported to be $\sim 500 \mathrm{nM}$ [223]. PF74 inhibits HIV-1 infection at various steps, including reverse transcription, nuclear entry, and integration [72, 188, 314, 317-321]. A distinct group of compounds (BI-1 and BI-2) also binds to the same binding pocket $[188,225]$, though they only interact with the CA-NTD. Recently, a series of capsid inhibitors that target this NTD-CTD interface with much improved potency and efficacy (GS-CA1 and GS-6207) have been developed [315, 316]. The $\mathrm{EC}_{50}$ of GS-CA1 against HIV- $1_{\text {IIIB }}$ in MT-4 cells is $\sim 240 \mathrm{pM}$, indicating that GS-CA1 has over 2,000-fold higher potency than PF74. This group of compounds that bind the capsid at the same region is currently being evaluated in vivo as a novel agent for HIV-1 treatment $[315,316]$ but has also served as an important research tool to dissect capsidmediated processes required for HIV-1 replication. Additionally, comprehensive characterization of drug resistant variants has informed how sequence changes in CA that emerged under selective drug pressure modulate virushost interactions and viral replicative capacity.

The structure of the PF74-CA complex has been determined [188, 189, 314]. Several amino acid changes in the PF74 binding pocket have been shown to affect PF74 binding to CA and the sensitivity of HIV-1 to this compound. For instance, the N57A mutation in CA abolished PF74 binding to CA and conferred nearly complete PF74 resistance $[95,187,320]$. N74D is another mutation in this pocket that diminished CA binding to the drug [187] and rendered HIV-1 less sensitive to PF74 [320]. Other mutations in the PF74 binding pocket, such as M66F, $\mathrm{K} 70 \mathrm{~A}$, and R173A, reduce PF74-CA binding to varying degrees [187, 189].

In vitro serial passage experiments with PF74 or its analogue were performed to identify resistance mutants. The first identified variant is called 5Mut, which carries five amino acid substitutions in CA: Q67H, K70R, H87P, T107N and L111I [223]. 5Mut displays reduced binding to PF74 and confers substantial resistance to PF74 [189, 223, 317]. Three mutations (Q67H, K70R, and T107N) in the drug binding pocket contribute to reduced capsid binding to PF74 [189, 223, 317]. Each of these mutations causes partial PF74 resistance [322]. The 5Mut virus shows a delayed replication kinetics, which is more profound in primary macrophages and $\mathrm{T}$ cells $[198,322]$. The 5 Mut virus differs from the WT virus at least in two properties, which may be the basis for the replication block. First, the 5Mut virus lost the ability to interact with CPSF6 and CypA and became less dependent on NUP153 and NUP358 for infection [198]. Second, cell-free assays showed that these five mutations increase intrinsic capsid stability [192, 317]. Consistent with this observation, 5Mut exhibited a phenotype of stable cores in virus-infected cells in two different assays [71, 317], although this change in capsid disassembly was not observed in another assay [319].

Another PF74 resistant variant was obtained after a long-term serial passage experiment and designated as 4Mut [198]. The 4Mut variant harbors a Q67H change that is also present in the 5Mut variant and reduces binding to PF74 [198]. Other mutations in the 4Mut variant are S41A in the CA-NTD and V165I and L172I in the CA-CTD [198]. This observation fits with the idea that PF74 targets the NTD-CTD interface [188, 189]. Replication of 4Mut is also profoundly impaired in primary cells [198]. The amino acid changes in the 4Mut variant block CA interactions with CPSF6 and NUP153 and reduced the dependence on HIV-1 nuclear entry cofactors [198]. Thus, 5Mut and 4Mut share some common properties.

These two PF74 resistant variants reduce capsid binding to both drug and host cofactors [198, 322]. Thus, it is unclear whether the reduced binding to cofactors has any role in drug resistance. This idea was supported by the observation that mutations that reduce capsid binding to host proteins, such as CypA and CPSF6, decrease PF74 sensitivity of HIV-1. Namely, both CPSF6-binding and CypA-binding deficient mutants were shown to be less sensitive to antiviral activity of PF74 [317, 320]. Furthermore, the K182A mutation, which reduces CA binding to CPSF6, confers partial resistant to low doses of PF74, even though the same mutation does not affect PF74 binding to the CA hexamer [320]. Thus, PF74 can competitively block CA-CPSF6 binding [187], but the lack of CA-CPSF6 binding did not enhance PF74 potency and it even reduces the antiviral activity against HIV-1. These host proteins can change the kinetics of uncoating. The altered uncoating kinetics may serve as one mechanism of resistance, as many of the capsid stability mutants confer partial resistance to PF74 [317, 323]. For instance, the hyper-stable mutant E45A binds to PF74 at a WT-level but is less sensitive to PF74 than the WT virus [317].

GS-CA1 and GS-6207 bind to the capsid at the same site as PF74 [315, 316, 324]. These compounds have been explored as a highly potent long-acting compounds in clinical trials [325]. Resistance-associated mutations for GS-CA1 were identified within the drug binding pocket at the following positions: L56, N57, M66, Q67, K70, N74 and T107 [315]. Serial passage of HIV-1 in the presence of GS-6207 selected for Q67H and N74D substitutions [316]. Additional selection experiments identified resistance mutations at the positions shared by those resistant to GS-CA1 [316]. These include L56I, M66I, K70N, Q67H/N74S and Q67H/T107N mutations [316]. M66I is a key change to confer drug resistance [326] and was shown to counteract inhibitory effects of these 
compounds on HIV-1 release and endogenous reverse transcription [97, 316].

Amino acid residues involved in resistance to these compounds exhibit a high sequence conservation among major HIV-1 clades. In addition, none of the resistant mutations for GS-6207 were identified in a study investigating plasma samples from 1500 patients infected with HIV-1 [327]. Consistent with these observations, all these mutations resistant to GS-CA1 and GS-6207, except for one, impair viral replicative capacity in both immortalized and primary $\mathrm{T}$ cells $[315,316]$. The degree of resistance appears to positively correlate with the magnitude of mutational effect on viral fitness. The M66I change conferred the highest resistance to GS-6207 but also drastically decreased viral infectivity. N57S and K70A mutants with an intermediate level of resistance suffered from a considerable loss of infectivity [316]. In contrast, the $\mathrm{Q} 67 \mathrm{H}$ substitution confers low-level resistance to GS-6207 and retains WT fitness [316]. Critically, this Q67H replacement was observed in one HIV-1 infected humanized animal treated with GS-CA1 [315]. Furthermore, the same Q67H mutation emerged in one HIV1-infected patient after a single administration of $20 \mathrm{mg}$ of GS-6207 [316]. It will be critical to continuously monitor how virus with the low-level resistance will evolve in a longer time scale.

Resistance selection studies for BI compounds of which binding site overlaps with those for PF74 and GS-6207 identified substitutions at A105 and T107 residues (A105T and T107A/N) [225]. Note that T107N was also selected for after in vitro adaptation against PF74 and GS-6207. Similarly, mutations (N57A and N57S) that reside in the drug binding pocket also enabled HIV-1 to escape from antiviral activity of BI-2 [197]. Overall, these observations support the idea that HIV-1 gains resistance to this group of compounds (GS-6207, PF74 and BI-2) through common mutational pathways. It is notable that amino acid changes at positions 105 and 107 in CA were selected in multiple occasions (see above). Mutations in these positions tend to reduce capsid binding to CPSF6. Thus, we speculate that the requirement for preserving CPSF6 binding underlies the observation that amino acid changes in this drug binding pocket are rare in vivo. Importantly, recent work showed that a transmitted founder variant is resistant to high doses of PF74 through a mechanism distinct from reduced PF74 binding [90]. Additionally, two SIVcpz strains displayed less sensitivity to PF74 and GS-CA1 [328]. Thus, additional studies of diverse HIV-1 and other lentiviruses may further uncover distinct viral strategies to evade inhibition by these capsid inhibitors.

Benzodiazepines and benzimidazoles belong to another group of capsid inhibitors that binds to the
CA-NTD [329]. These compounds either block virus particle production or capsid maturation by interfering with the formation of the NTD/CTD contacts that are critical for stabilizing CA hexamers and pentamers. Resistant mutations were found at the CA-NTD that are close to the drug binding site as well as in the CA-CTD [329]. Interestingly, these CA-CTD mutations, such as G208R and E213G, were often identified together with binding mutations in the CA-NTD. These CA-CTD mutations reside at the trimeric interfaces and were shown to promote CA-NC assembly in cell-free assays, suggesting the possibility that indirect resistant mutations likely modulate the stability of the capsid lattice [329].

Maturation inhibitors (MIs), such as bevirimat (BVM), bind immature virus particles and block HIV-1 infection by interfering with Gag cleavage at the CA-SP1 junction [330] and thus preventing mature capsid formation. While MIs are not classified as capsid-targeting inhibitors, their resistance can be mediated by a few distinct groups of amino acid changes in the CA domain [314, 331-338]. Two groups of resistant mutations are notable. One group contains mutations at the CA-SP1 boundary region. Mutations at both G225 and H226 residues impair virus fitness [332, 336, 339]. In contrast, a V230I substitution, which occurred in a resistant variant after in vitro evolution in the presence of BVM [335], is also present in circulating HIV-1 variants [340]. Thus, sequence variability in CA among primary strains can be a determinant for the sensitivity to HIV-1 inhibitors.

A second region that harbors MI resistant mutations is the MHR in the CA-CTD [336, 337]. These mutations were discovered using a structurally distinct MI called PF96 or second-generation MIs [336, 337]. Consistent with the critical role played by the MHR during virus particle production, most of the resistant mutations in the MHR attenuated viral replication [336]. Mechanistically, two of the mutants, G156E and P157S, were shown to have defects in Gag multimerization [48, 336]. These amino acid residues are located close to K157, which is one of the key amino acid residues responsible for recruiting IP6 in immature virus particles. In fact, recent work revealed an intriguing link between IP6 and MIs; IP6-deficient mutants were shown to be resistant to MIs [47] and rescued by a T-to-I substitution at position 8 of SP1, which has a similar effect to MIs [48]. Unexpectedly, one MI resistant mutation (P157A) in the MHR remains replication-competent even in primary cells [337]. Alanine at position 157 is observed in some SIV strains. Thus, some amino acid residues in the MHR may be tolerable to mutational effects without fitness loss, an observation that is relevant to further consideration of drug resistant mutations in CA. 


\section{Conclusions}

This review article has summarized recent findings about how sequence variation in CA causes a remarkable range of variation in phenotypic properties of HIV-1. Capsid interaction with host factors is a key feature that defines the replication strategy of HIV-1. Numerous amino acid changes in CA perturb capsid-host interactions and consequently change various viral phenotypes, including a profound defect in infectivity. Previous work uncovered multiple sites of vulnerability in the viral capsid, some of which are currently being explored as a target for therapeutic interventions. On the other hand, there are several cases in which the loss of host factor utilization by HIV-1 (e.g., CypA, and CPSF6) has negligible impacts on viral fitness, even though it can alter the timing and location of capsid disassembly, change nuclear entry pathways, and also diminish the unique preference of HIV-1 integration targeting. These observations are in accord with other studies indicating that the requirement of these host factors is not conserved among diverse lentiviruses. Thus, these results underscore a striking flexibility in various post-entry processes mediated by the viral capsid. Overall, these findings highlight an unexpected duality of the viral capsid: extreme genetic fragility and functional flexibility.

Another lesson learned from previous work is that a single amino acid replacement in CA can result in multiple, and sometimes independent phenotypic outcomes (Table 1). For instance, the N74 residue is critical for CA binding to CPSF6 [93]. As such, the N74D mutation leads to phenotypes similar to those caused by the loss of CA binding to CPSF6, such as provirus integration into genepoor regions $[105,214]$. The same amino acid change also renders HIV-1 sensitive to antiviral activity of TRIM34, but this differential sensitivity appears to be independent from CA interactions CPSF6 interactions [219]. Another notable example is a conserved arginine residue at position 18, which has been implicated in nucleotide transport and binding to IP6 as well as FEZ1 [45, 96, 101, 102]. These examples highlight the difficulty in attributing an infectivity defect to a single mutational effect, and thus underscore a need for a combinatory approach to define the role of each amino acid of CA in diverse functions of the HIV-1 capsid.

Several questions remain unresolved. In addition to well-characterized CPSF6 and CypA, many other cellular proteins interact with the viral capsid, but their binding modes and utilization by various mutants or other groups of lentiviruses have been less well investigated (e.g., BICD2, FEZ1, and TRN-1) [101, 127, 341-343]. Our understanding of capsid-dependent restriction is incomplete. Previous work identified several different mechanisms of capsid-dependent post-entry blocks that are independent from TRIM5 and MX2 [312, 344-347]. Interestingly, some of such restriction can be attenuated or sensitized by amino acid changes in CA regions that mediate CypA or CPSF6 binding [138, 312, 347, 348]. For instance, antiviral activity elicited by type I IFN responses was shown to be more potent against certain HIV-1 variants carrying CA mutations [138]. In addition, human blood cells express a capsid-specific factor that blocks viruses belonging to the SIVsm/mac lineage [346], while non-human primate and non-primate species encode unknown restriction factors that inhibit HIV-1 in a CAdependent manner [312, 347]. Finally, lentivirus restriction that is dependent on both envelope and capsid has been described [344, 345] in which one type of restriction, called Lv2 [344], is determined by N74D, G89V, and G94D mutations [348]. Continued investigation of these various types of unresolved capsid-dependent restriction will allow us to better define the exact composition of the antiviral defense system in the host that likely played an important role for shaping the evolution of lentiviruses.

Another challenge relates to the viral genetic background. An increasing number of studies have characterized circulating HIV-1 variants, but most work relies on a handful of lab-adapted HIV-1 variants. Previous work showed that even closely related HIV-1 variants (LAI vs NL4-3) differ in their mutational effects [220]. In other instances, single amino acid changes result in different phenotypic outcomes depending on the viral sequence background [170, 221, 339]. HIV-1 genetic context matters for viral evolution, as the viral sequence background influences how HIV-1 adapts to cellular immunity in vivo [349]. Deep scanning mutagenesis, a technique to dissect mutational effects of each residue in host or viral proteins $[350,351]$, has been applied to studying the mutational tolerance of the HIV-1 genome and the evolutionary process during HIV-1 adaptation to antiviral agents [352355]. Future studies that combine such technique with the utilization of different genetic backgrounds should provide new insights into epistatic interactions in the viral capsid and enhance our understanding of the evolutional potential of the HIV-1 capsid.

\section{Abbreviations}

BIV: Bovine immunodeficiency virus; CGAS: Cyclic GMP-AMP synthase; CM: Cynomolgus macaque; CPSF6: Cleavage and polyadenylation specificity factor subunit 6; CsA: Cyclosporine A; CTD: C-terminal domain; CypA: Cyclophilin A; $\mathrm{EC}_{50}$ : Effective concentration 50; EIAV: Equine infectious anemia virus; FIV: Ferine immunodeficiency virus; HIV: Human immunodeficiency virus; IFN: Interferon; IP6: Inositol hexakisphosphate; IPMK: Inositol-polyphosphate multikinase; IPPK: Inositol-pentakisphosphate 2-kinase; MHR: Major homology region; MX2: MX Dynamin like GTPase 2; N-MLV: N-tropic murine leukemia virus; NTD: N-terminal domain; NPC: Nuclear pore complex; PIC: Pre-integration complex; RM: Rhesus macaque; RSV: Rous sarcoma virus; SIV: Simian immunodeficiency virus; TRN-1: Transportin-1; TRIM5: Tripartite motif containing 5. 


\section{Acknowledgements}

The authors acknowledge Axel Guzmán Solís for his input into early drafts of this manuscript. We are also grateful to Mohammad Adnan Siddiqui, Lily Tsai, and Raajita Bose for their comments on the manuscript.

\section{Authors' contributions}

AS and MY conceived, developed, organized, co-wrote and edit the manuscript. All authors read and approved the final version of the paper

\section{Funding}

This work was supported by NIH Grant R01Al100720 (to MY), by the Japan Agency for Medical Research and Development, AMED Grants 21jk0210039, 20fk0108163, 20fk0108451, 20fk0410033, 21fk0410033, 20wm0325009 and 21 wm0325009 (AS), JSPS KAKENHI Grant-in-Aid for Scientific Research (C) Grant 19 K06382 (AS), and CRDF Global Grant JP21jk0210039 (AS). The funders have no role in the preparation of this article and the content is solely the responsibility of the authors.

\section{Availability of data and materials}

Not applicable.

\section{Declarations}

\section{Ethics approval and consent to participate}

Not applicable.

\section{Consent for publication}

Not applicable.

\section{Competing interests}

The authors declare that they have no competing interests.

\section{Author details}

${ }^{1}$ Department of Veterinary Medicine, Faculty of Agriculture, University of Miyazaki, Miyazaki, Miyazaki, Japan. ${ }^{2}$ Center for Animal Disease Control, University of Miyazaki, Miyazaki, Miyazaki, Japan. ${ }^{3}$ Aaron Diamond AIDS Research Center, Columbia University Vagelos College of Physicians and Surgeons, New York, NY, USA.

Received: 6 July 2021 Accepted: 13 October 2021

Published online: 26 October 2021

\section{References}

1. Campbell EM, Hope TJ. HIV-1 capsid: the multifaceted key player in HIV-1 infection. Nat Rev Microbiol. 2015;13:471-83.

2. Ganser-Pornillos BK, Yeager M, Pornillos O. Assembly and architecture of HIV. Adv Exp Med Biol. 2012;726:441-65.

3. Perilla JR, Gronenborn AM. Molecular architecture of the retroviral capsid. Trends Biochem Sci. 2016:41:410-20.

4. Fassati A. Multiple roles of the capsid protein in the early steps of HIV-1 infection. Virus Res. 2012;170:15-24.

5. Novikova M, Zhang Y, Freed EO, Peng K. Multiple roles of HIV-1 capsid during the virus replication cycle. Virol Sin. 2019;34:119-34.

6. Scoca V, Di Nunzio F. The HIV-1 capsid: from structural component to key factor for host nuclear invasion. Viruses. 2021;13:273.

7. Arhel N. Revisiting HIV-1 uncoating. Retrovirology. 2010;7:96.

8. Ambrose Z, Aiken C. HIV-1 uncoating: connection to nuclear entry and regulation by host proteins. Virology. 2014;454-455:371-9.

9. Yamashita M, Engelman AN. Capsid-dependent host factors in HIV-1 infection. Trends Microbiol. 2017:25:741-55.

10. Wilbourne M, Zhang P. Visualizing HIV-1 capsid and its interactions with antivirals and host factors. Viruses. 2021:13:246.

11. Temple J, Tripler TN, Shen Q, Xiong Y. A snapshot of HIV-1 capsid-host interactions. Curr Res Struct Biol. 2020;2:222-8.

12. Thenin-Houssier S, Valente ST. HIV-1 capsid inhibitors as antiretroviral agents. Curr HIV Res. 2016:14:270-82.

13. Carnes SK, Sheehan JH, Aiken C. Inhibitors of the HIV-1 capsid, a target of opportunity. Curr Opin HIV AIDS. 2018;13:359-65.
14. Ganser-Pornillos BK, Yeager M, Sundquist WI. The structural biology of HIV assembly. Curr Opin Struct Biol. 2008;18:203-17.

15. Zhang W, Cao S, Martin JL, Mueller JD, Mansky LM. Morphology and ultrastructure of retrovirus particles. AIMS Biophys. 2015;2:343-69.

16. Sundquist WI, Kräusslich H-G. HIV-1 assembly, budding, and maturation. Cold Spring Harbor Perspect Med. 2012;2:a006924.

17. Freed EO. HIV-1 assembly, release and maturation. Nat Rev Microbiol. 2015;13:484-96.

18. Wang CT, Barklis E. Assembly, processing, and infectivity of human immunodeficiency virus type 1 gag mutants. J Virol. 1993;67:4264-73.

19. Dorfman T, Bukovsky A, Ohagen A, Höglund S, Göttlinger HG. Functional domains of the capsid protein of human immunodeficiency virus type 1. J Virol. 1994;68:8180-7.

20. Reicin AS, Paik S, Berkowitz RD, Luban J, Lowy I, Goff SP. Linker insertion mutations in the human immunodeficiency virus type 1 gag gene: effects on virion particle assembly, release, and infectivity. J Virol. 1995;69:642-50.

21. Fitzon T, Leschonsky B, Bieler K, Paulus C, Schröder J, Wolf H, Wagner R. Proline residues in the HIV-1 NH2-terminal capsid domain: structure determinants for proper core assembly and subsequent steps of early replication. Virology. 2000;268:294-307.

22. von Schwedler UK, Stray KM, Garrus JE, Sundquist WI. Functional surfaces of the human immunodeficiency virus type 1 capsid protein. J Virol. 2003;77:5439-50.

23. Manocheewa S, Swain JV, Lanxon-Cookson E, Rolland M, Mullins Jl. Fitness costs of mutations at the HIV-1 capsid hexamerization interface. PLOS ONE. 2013:8:e66065.

24. Rihn SJ, Wilson SJ, Loman NJ, Alim M, Bakker SE, Bhella D, Gifford RJ, Rixon FJ, Bieniasz PD. Extreme genetic fragility of the HIV-1 capsid. PLoS Pathog. 2013;9:e1003461.

25. Gamble TR, Yoo S, Vajdos FF, von Schwedler UK, Worthylake DK, Wang $\mathrm{H}$, McCutcheon JP, Sundquist WI, Hill CP. Structure of the carboxylterminal dimerization domain of the HIV-1 capsid protein. Science. 1997;278:849-53.

26. Accola MA, Höglund S, Göttlinger HG. A putative alpha-helical structure which overlaps the capsid-p2 boundary in the human immunodeficiency virus type 1 Gag precursor is crucial for viral particle assembly. J Virol. 1998:72:2072-8.

27. Liang C, Hu J, Russell RS, Roldan A, Kleiman L, Wainberg MA. Characterization of a putative alpha-helix across the capsid-SP1 boundary that is critical for the multimerization of human immunodeficiency virus type 1 gag. J Virol. 2002:76:11729-37.

28. Liang C, Hu J, Whitney JB, Kleiman L, Wainberg MA. A structurally disordered region at the $C$ terminus of capsid plays essential roles in multimerization and membrane binding of the gag protein of human immunodeficiency virus type 1. J Virol. 2003;77:1772-83.

29. Abdurahman S, Höglund S, Goobar-Larsson L, Vahlne A. Selected amino acid substitutions in the C-terminal region of human immunodeficiency virus type 1 capsid protein affect virus assembly and release. J Gen Virol. 2004;85:2903-13.

30. Melamed D, Mark-Danieli M, Kenan-Eichler M, Kraus O, Castiel A, Laham N, Pupko T, Glaser F, Ben-Tal N, Bacharach E. The conserved carboxy terminus of the capsid domain of human immunodeficiency virus type $1 \mathrm{gag}$ protein is important for virion assembly and release. J Virol. 2004:78:9675-88.

31. Strambio-de-Castillia C, Hunter E. Mutational analysis of the major homology region of Mason-Pfizer monkey virus by use of saturation mutagenesis. J Virol. 1992;66:7021-32.

32. Mammano F, Ohagen A, Höglund S, Göttlinger HG. Role of the major homology region of human immunodeficiency virus type 1 in virion morphogenesis. J Virol. 1994;68:4927-36.

33. Craven RC, Leure-duPree AE, Weldon RA, Wills JW. Genetic analysis of the major homology region of the Rous sarcoma virus Gag protein. J virol. 1995:69:4213-27.

34. Chang Y-F, Wang S-M, Huang K-J, Wang C-T. Mutations in capsid major homology region affect assembly and membrane affinity of HIV-1 Gag. J Mol Biol. 2007;370:585-97.

35. Tanaka M, Robinson BA, Chutiraka K, Geary CD, Reed JC, Lingappa JR. Mutations of conserved residues in the major homology region arrest assembling HIV-1 gag as a membrane-targeted intermediate containing genomic RNA and cellular proteins. J Virol. 2016;90:1944-63. 
36. Novikova M, Adams LJ, Fontana J, Gres AT, Balasubramaniam M, Winkler DC, Kudchodkar SB, Soheilian F, Sarafianos SG, Steven AC, Freed EO. Identification of a structural element in HIV-1 gag required for virus particle assembly and maturation. mBio 2018;9.

37. Wagner JM, Zadrozny KK, Chrustowicz J, Purdy MD, Yeager M, GanserPornillos BK, Pornillos O. Crystal structure of an HIV assembly and maturation switch. eLife. 2016:5.

38. Kucharska I, Ding P, Zadrozny KK, Dick RA, Summers MF, Ganser-Pornillos BK, Pornillos O. Biochemical reconstitution of HIV-1 assembly and maturation. J Virol. 2020;94.

39. Joshi A, Nagashima K, Freed EO. Mutation of dileucine-like motifs in the human immunodeficiency virus type 1 capsid disrupts virus assembly, gag-gag interactions, gag-membrane binding, and virion maturation. J Virol. 2006;80:7939-51.

40. Robinson BA, Reed JC, Geary CD, Swain JV, Lingappa JR. A temporospatial map that defines specific steps at which critical surfaces in the Gag MA and CA domains act during immature HIV-1 capsid assembly in cells. J Virol. 2014;88:5718-41.

41. Lingappa JR, Reed JC, Tanaka M, Chutiraka K, Robinson BA. How HIV-1 Gag assembles in cells: putting together pieces of the puzzle. Virus Res. 2014;193:89-107.

42. Dick RA, Mallery DL, Vogt VM, James LC. IP6 regulation of HIV capsid assembly, stability, and uncoating. Viruses. 2018;10:640.

43. Dostálková A, Kaufman F, Kř̌ižová I, Vokatá B, Ruml T, Rumlová M. In vitro quantification of the effects of IP6 and other small polyanions on immature HIV-1 particle assembly and core stability. J Virol. 2020;94.

44. Sowd GA, Aiken C. Inositol phosphates promote HIV-1 assembly and maturation to facilitate viral spread in human CD4+ T cells. PLoS Pathog. 2021;17:e1009190.

45. Dick RA, Zadrozny KK, Xu C, Schur FKM, Lyddon TD, Ricana CL, Wagner JM, Perilla JR, Ganser-Pornillos BK, Johnson MC, et al. Inositol phosphates are assembly co-factors for HIV-1. Nature. 2018;560:509-12.

46. Mallery DL, Faysal KMR, Kleinpeter A, Wilson MSC, Vaysburd M, Fletcher AJ, Novikova M, Böcking T, Freed EO, Saiardi A, James LC. Cellular IP6 levels limit HIV production while viruses that cannot efficiently package IP6 are attenuated for infection and replication. Cell Rep. 2019;29:39833996.e3984.

47. Mallery DL, Kleinpeter AB, Renner N, Faysal KMR, Novikova M, Kiss L, Wilson MSC, Ahsan B, Ke Z, Briggs JAG, et al. A stable immature lattice packages IP6 for HIV capsid maturation. Sci Adv. 2021;7.

48. Poston D, Zang T, Bieniasz P. Derivation and characterization of an HIV-1 mutant that rescues IP6 binding deficiency. Retrovirology. 2021;18:25.

49. Ricana $C L$, Lyddon TD, Dick RA, Johnson MC. Primate lentiviruses require Inositol hexakisphosphate (IP6) or inositol pentakisphosphate (IP5) for the production of viral particles. PLoS Pathog. 2020;16:e1008646.

50. Dick RA, Xu C, Morado DR, Kravchuk V, Ricana CL, Lyddon TD, Broad AM, Feathers JR, Johnson MC, Vogt VM, et al. Structures of immature EIAV Gag lattices reveal a conserved role for IP6 in lentivirus assembly. PLoS Pathog. 2020;16:e1008277

51. Mattei S, Schur FK, Briggs JA. Retrovirus maturation-an extraordinary structural transformation. Curr Opin Virol. 2016:18:27-35.

52. Pornillos O, Ganser-Pornillos BK. Maturation of retroviruses. Curr Opin Virol. 2019;36:47-55.

53. von Schwedler UK, Stemmler TL, Klishko VY, Li S, Albertine KH, Davis DR, Sundquist WI. Proteolytic refolding of the HIV-1 capsid protein aminoterminus facilitates viral core assembly. EMBO J. 1998;17:1555-68.

54. Tang S, Murakami T, Agresta BE, Campbell S, Freed EO, Levin JG. Human immunodeficiency virus type $1 \mathrm{~N}$-terminal capsid mutants that exhibit aberrant core morphology and are blocked in initiation of reverse transcription in infected cells. J Virol. 2001:75:9357-66.

55. Scholz I, Arvidson B, Huseby D, Barklis E. Virus particle core defects caused by mutations in the human immunodeficiency virus capsid N-terminal domain. J Virol. 2005;79:1470-9.

56. Yufenyuy EL, Aiken C. The NTD-CTD intersubunit interface plays a critical role in assembly and stabilization of the HIV-1 capsid. Retrovirology. 2013;10:29.

57. Zhao G, Perilla JR, Yufenyuy EL, Meng X, Chen B, Ning J, Ahn J, Gronenborn AM, Schulten K, Aiken C, Zhang P. Mature HIV-1 capsid structure by cryo-electron microscopy and all-atom molecular dynamics. Nature. 2013;497:643-6.
58. Craveur P, Gres AT, Kirby KA, Liu D, Hammond JA, Deng Y, Forli S, Goodsell DS, Williamson JR, Sarafianos SG, Olson AJ. Novel intersubunit interaction critical for HIV-1 core assembly defines a potentially targetable inhibitor binding pocket. mBio. 2019;10.

59. Brun S, Solignat M, Gay B, Bernard E, Chaloin L, Fenard D, Devaux C, Chazal N, Briant L. VSV-G pseudotyping rescues HIV-1 CA mutations that impair core assembly or stability. Retrovirology. 2008;5:57.

60. Cairns TM, Craven RC. Viral DNA synthesis defects in assembly-competent Rous sarcoma virus CA mutants. J Virol. 2001:75:242-50.

61. Forshey BM, von Schwedler U, Sundquist WI, Aiken C. Formation of a human immunodeficiency virus type 1 core of optimal stability is crucial for viral replication. J Virol. 2002;76:5667-77.

62. Tang S, Murakami T, Cheng N, Steven AC, Freed EO, Levin JG. Human immunodeficiency virus type $1 \mathrm{~N}$-terminal capsid mutants containing cores with abnormally high levels of capsid protein and virtually no reverse transcriptase. J Virol. 2003;77:12592-602.

63. Wacharapornin P, Lauhakirti D, Auewarakul P. The effect of capsid mutations on HIV-1 uncoating. Virology. 2007;358:48-54.

64. Jiang J, Ablan SD, Derebail S, Hercík K, Soheilian F, Thomas JA, Tang S, Hewlett I, Nagashima K, Gorelick RJ, et al. The interdomain linker region of HIV-1 capsid protein is a critical determinant of proper core assembly and stability. Virology. 2011;421:253-65.

65. Inagaki N, Takeuchi H, Yokoyama M, Sato H, Ryo A, Yamamoto H, Kawada M, Matano T. A structural constraint for functional interaction between $\mathrm{N}$-terminal and C-terminal domains in simian immunodeficiency virus capsid proteins. Retrovirology. 2010;7:90.

66. Francis AC, Marin M, Shi J, Aiken C, Melikyan GB. Time-resolved imaging of single HIV-1 uncoating in vitro and in living cells. PLoS Pathog. 2016:12:e1005709.

67. Márquez CL, Lau D, Walsh J, Shah V, McGuinness C, Wong A, Aggarwal A, Parker MW, Jacques DA, Turville S, Böcking T. Kinetics of HIV-1 capsid uncoating revealed by single-molecule analysis. eLife. 2018;7.

68. Xu C, Fischer DK, Rankovic S, Li W, Dick RA, Runge B, Zadorozhnyi R, Ahn J, Aiken C, Polenova T, et al. Permeability of the HIV-1 capsid to metabolites modulates viral DNA synthesis. PLoS Biol. 2020;18:e3001015.

69. Hulme $A E$, Perez $O$, Hope TJ. Complementary assays reveal a relationship between HIV-1 uncoating and reverse transcription. Proc Natl Acad Sci USA. 2011;108:9975-80.

70. Burdick RC, Hu W-S, Pathak VK. Nuclear import of APOBEC3Flabeled HIV-1 preintegration complexes. Proc Natl Acad Sci USA. 2013;110:E4780-4789.

71. Xu H, Franks T, Gibson G, Huber K, Rahm N, Strambio De Castillia C, Luban J, Aiken C, Watkins S, Sluis-Cremer N, Ambrose Z. Evidence for biphasic uncoating during HIV-1 infection from a novel imaging assay. Retrovirology. 2013;10:70

72. Peng K, Muranyi W, Glass B, Laketa V, Yant SR, Tsai L, Cihlar T, Müller B, Kräusslich H-G. Quantitative microscopy of functional HIV post-entry complexes reveals association of replication with the viral capsid. Elife. 2014;3:e04114

73. Mamede Jl, Cianci GC, Anderson MR, Hope TJ. Early cytoplasmic uncoating is associated with infectivity of HIV-1. Proc Natl Acad Sci USA 2017;114:E7169-78.

74. Francis AC, Melikyan GB. Live-cell imaging of early steps of single HIV-1 infection. Viruses. 2018;10:275.

75. Stremlau M, Perron M, Lee M, Li Y, Song B, Javanbakht H, Diaz-Griffero F, Anderson DJ, Sundquist WI, Sodroski J. Specific recognition and accelerated uncoating of retroviral capsids by the TRIM5alpha restriction factor. Proc Natl Acad Sci USA. 2006:103:5514-9.

76. Kutluay SB, Perez-Caballero D, Bieniasz PD. Fates of retroviral core components during unrestricted and TRIM5-restricted infection. PLoS Pathog. 2013;9:e1003214.

77. Yang Y, Luban J, Diaz-Griffero F. The fate of HIV-1 capsid: a biochemical assay for HIV-1 uncoating. Methods Mol Biol. 2014;1087:29-36.

78. Shi J, Aiken C. Saturation of TRIM5 alpha-mediated restriction of HIV-1 infection depends on the stability of the incoming viral capsid. Virology. 2006:350:493-500.

79. Hulme AE, Hope TJ. The cyclosporin A washout assay to detect HIV-1 uncoating in infected cells. Methods Mol Biol. 2014;1087:37-46.

80. Jun S, Ke D, Debiec K, Zhao G, Meng X, Ambrose Z, Gibson GA, Watkins SC, Zhang P. Direct visualization of HIV-1 with correlative live-cell 
microscopy and cryo-electron tomography. Structure (London, England: 1993). 2011;19:1573-81.

81. Hulme AE, Kelley Z, Okocha EA, Hope TJ. Identification of capsid mutations that alter the rate of HIV-1 uncoating in infected cells. JVirol. 2015;89:643-51.

82. Da Silva SC, Tartour K, Cimarelli A. A novel entry/uncoating assay reveals the presence of at least two species of viral capsids during synchronized HIV-1 infection. PLoS Pathog. 2016;12:e1005897.

83. Francis AC, Melikyan GB. Single HIV-1 imaging reveals progression of infection through CA-dependent steps of docking at the nuclear pore, uncoating, and nuclear transport. Cell Host Microbe. 2018;23:536-548. e536.

84. Ingram Z, Taylor M, Okland G, Martin R, Hulme AE. Characterization of HIV-1 uncoating in human microglial cell lines. Virol J. 2020;17:31.

85. Eschbach JE, Elliott JL, Li W, Zadrozny KK, Davis K, Mohammed SJ, Lawson DQ, Pornillos O, Engelman AN, Kutluay SB. Capsid lattice destabilization leads to premature loss of the viral genome and integrase enzyme during HIV-1 infection. J Virol. 2020;95.

86. Forshey BM, Shi J, Aiken C. Structural requirements for recognition of the human immunodeficiency virus type 1 core during host restriction in owl monkey cells. J Virol. 2005;79:869-75.

87. Cosnefroy O, Murray PJ, Bishop KN. HIV-1 capsid uncoating initiates after the first strand transfer of reverse transcription. Retrovirology. 2016;13:58.

88. Dismuke DJ, Aiken C. Evidence for a functional link between uncoating of the human immunodeficiency virus type 1 core and nuclear import of the viral preintegration complex. J Virol. 2006:80:3712-20.

89. Yamashita M, Perez O, Hope TJ, Emerman M. Evidence for direct involvement of the capsid protein in HIV infection of nondividing cells. PLoS Pathog. 2007;3:1502-10.

90. Siddiqui MA, Saito A, Halambage UD, Ferhadian D, Fischer DK, Francis AC, Melikyan GB, Ambrose Z, Aiken C, Yamashita M. A novel phenotype links HIV-1 capsid stability to CGAS-mediated DNA sensing. J Virol. 2019;93.

91. Leschonsky B, Ludwig C, Bieler K, Wagner R. Capsid stability and replication of human immunodeficiency virus type 1 are influenced critically by charge and size of Gag residue 183. J Gen Virol. 2007;88:207-16.

92. Burdick RC, Delviks-Frankenberry KA, Chen J, Janaka SK, Sastri J, Hu W-S, Pathak VK. Dynamics and regulation of nuclear import and nuclear movements of HIV-1 complexes. PLoS Pathog. 2017;13:e1006570.

93. Lee K, Ambrose Z, Martin TD, Oztop I, Mulky A, Julias JG, Vandegraaff $\mathrm{N}$, Baumann JG, Wang R, Yuen W, et al. Flexible use of nuclear import pathways by HIV-1. Cell Host Microbe. 2010;7:221-33.

94. Matreyek KA, Engelman A. The requirement for nucleoporin NUP153 during human immunodeficiency virus type 1 infection is determined by the viral capsid. J Virol. 2011;85:7818-27.

95. Matreyek KA, Yücel SS, Li X, Engelman A. Nucleoporin NUP153 phenylalanine-glycine motifs engage a common binding pocket within the HIV-1 capsid protein to mediate lentiviral infectivity. PLoS Pathog. 2013;9:e1003693.

96. Mallery DL, Márquez CL, McEwan WA, Dickson CF, Jacques DA, Anandapadamanaban M, Bichel K, Towers GJ, Saiardi A, Böcking T, James LC. IP6 is an HIV pocket factor that prevents capsid collapse and promotes DNA synthesis. eLife. 2018;7.

97. Christensen DE, Ganser-Pornillos BK, Johnson JS, Pornillos O, Sundquist WI. Reconstitution and visualization of HIV-1 capsid-dependent replication and integration in vitro. Science (New York, NY) 2020;370.

98. Jennings J, Shi J, Varadarajan J, Jamieson PJ, Aiken C. The host cell metabolite inositol hexakisphosphate promotes efficient endogenous HIV-1 reverse transcription by stabilizing the viral capsid. mBio. 2020;11.

99. Renner N, Mallery DL, Faysal KMR, Peng W, Jacques DA, Böcking T, James LC. A lysine ring in HIV capsid pores coordinates IP6 to drive mature capsid assembly. PLoS Pathog. 2021;17:e1009164.

100. Malikov V, da Silva ES, Jovasevic V, Bennett G, de Souza Aranha Vieira DA, Schulte B, Diaz-Griffero F, Walsh D, Naghavi MH. HIV-1 capsids bind and exploit the kinesin-1 adaptor FEZ1 for inward movement to the nucleus. Nat Commun. 2015;6:6660.

101. Huang PT, Summers BJ, Xu C, Perilla JR, Malikov V, Naghavi MH, Xiong Y. FEZ1 is recruited to a conserved cofactor site on capsid to promote HIV-1 trafficking. Cell Rep. 2019;28:2373-2385e2377.
102. Jacques DA McEwan WA, Hilditch L. Price AJ, Towers GJ, James LC. HIV-1 uses dynamic capsid pores to import nucleotides and fuel encapsidated DNA synthesis. Nature. 2016:536:349-53.

103. Ganser-Pornillos BK, von Schwedler UK, Stray KM, Aiken C, Sundquist WI. Assembly properties of the human immunodeficiency virus type 1 CA protein. J Virol. 2004;78:2545-52.

104. Luban J, Bossolt KL, Franke EK, Kalpana GV, Goff SP. Human immunodeficiency virus type $1 \mathrm{Gag}$ protein binds to cyclophilins A and B. Cell. 1993:73:1067-78.

105. Schaller T, Ocwieja KE, Rasaiyaah J, Price AJ, Brady TL, Roth SL, Hué S, Fletcher AJ, Lee K, Kewal Ramani VN, et al. HIV-1 capsid-cyclophilin interactions determine nuclear import pathway, integration targeting and replication efficiency. PLoS Pathog. 2011;7:e1002439.

106. Di Nunzio F, Danckaert A, Fricke T, Perez P, Fernandez J, Perret E, Roux P, Shorte S, Charneau P, Diaz-Griffero F, Arhel NJ. Human nucleoporins promote HIV-1 docking at the nuclear pore, nuclear import and integration. PLoS ONE. 2012;7:e46037.

107. Li Y, Kar AK, Sodroski J. Target cell type-dependent modulation of human immunodeficiency virus type 1 capsid disassembly by cyclophilin A. JVirol. 2009:83:10951-62.

108. Tipper C, Sodroski JG. Contribution of glutamine residues in the helix 4-5 loop to capsid-capsid interactions in simian immunodeficiency virus of macaques. J Virol. 2014;88:10289-302.

109. Gamble TR, Vajdos FF, Yoo S, Worthylake DK, Houseweart M, Sundquist WI, Hill CP. Crystal structure of human cyclophilin A bound to the amino-terminal domain of HIV-1 capsid. Cell. 1996;87:1285-94.

110. Franke EK, Yuan HE, Luban J. Specific incorporation of cyclophilin A into HIV-1 virions. Nature. 1994;372:359-62.

111. Braaten D, Franke EK, Luban J. Cyclophilin A is required for an early step in the life cycle of human immunodeficiency virus type 1 before the initiation of reverse transcription. J Virol. 1996:70:3551-60.

112. Bukovsky AA, Weimann A, Accola MA, Göttlinger HG. Transfer of the HIV-1 cyclophilin-binding site to simian immunodeficiency virus from Macaca mulatta can confer both cyclosporin sensitivity and cyclosporin dependence. Proc Natl Acad Sci USA. 1997:94:10943-8.

113. Yoo S, Myszka DG, Yeh C, McMurray M, Hill CP, Sundquist WI. Molecular recognition in the HIV-1 capsid/cyclophilin A complex. J Mol Biol. 1997:269:780-95.

114. Yin L, Braaten D, Luban J. Human immunodeficiency virus type 1 replication is modulated by host cyclophilin A expression levels. J Virol. 1998;72:6430-6.

115. Braaten D, Luban J. Cyclophilin A regulates HIV-1 infectivity, as demonstrated by gene targeting in human T cells. EMBO J. 2001;20:1300-9.

116. Petrillo C, Cesana D, Piras F, Bartolaccini S, Naldini L, Montini E, KajasteRudnitski A. Cyclosporin a and rapamycin relieve distinct lentiviral restriction blocks in hematopoietic stem and progenitor cells. Mol Ther J Am Soc Gene Ther. 2015:23:352-62.

117. Barateau V, Nguyen X-N, Bourguillault F, Berger G, Cordeil S, Cimarelli A. The susceptibility of primate lentiviruses to nucleosides and $\mathrm{Vpx}$ during infection of dendritic cells is regulated by CA. J Virol. 2015;89:4030-4.

118. Selyutina A, Persaud M, Simons LM, Bulnes-Ramos A, Buffone C, Martinez-Lopez A, Scoca V, Di Nunzio F, Hiatt J, Marson A, et al. Cyclophilin A prevents HIV-1 restriction in lymphocytes by blocking human TRIM5a binding to the viral core. Cell Rep. 2020;30:3766-3777.e3766.

119. Ackerson B, Rey O, Canon J, Krogstad P. Cells with high cyclophilin A content support replication of human immunodeficiency virus type 1 Gag mutants with decreased ability to incorporate cyclophilin A. J Virol. 1998:72:303-8

120. Kim K, Dauphin A, Komurlu S, McCauley SM, Yurkovetskiy L, Carbone C, DiehI WE, Strambio-De-Castillia C, Campbell EM, Luban J. Cyclophilin A protects HIV-1 from restriction by human TRIM5a. Nat Microbiol. 2019:4:2044-51.

121. Zhong Z, Ning J, Boggs EA, Jang S, Wallace C, Telmer C, Bruchez MP, Ahn J, Engelman AN, Zhang P, et al. Cytoplasmic CPSF6 regulates HIV-1 capsid trafficking and infection in a cyclophilin A-dependent manner. mBio. 2021:12.

122. Engelman AN. HIV capsid and integration targeting. Viruses. 2021:13:125.

123. Hilditch L, Towers GJ. A model for cofactor use during HIV-1 reverse transcription and nuclear entry. Curr Opin Virol. 2014:4:32-6. 
124. Kane M, Rebensburg SV, Takata MA, Zang TM, Yamashita M, Kvaratskhelia M, Bieniasz PD. Nuclear pore heterogeneity influences HIV-1 infection and the antiviral activity of MX2. eLife. 2018;7.

125. Dharan A, Talley S, Tripathi A, Mamede Jl, Majetschak M, Hope TJ, Campbell EM. KIF5B and Nup358 cooperatively mediate the nuclear import of HIV-1 during infection. PLoS Pathog. 2016;12:e1005700.

126. Meehan AM, Saenz DT, Guevera R, Morrison JH, Peretz M, Fadel HJ, Hamada M, van Deursen J, Poeschla EM. A cyclophilin homology domain-independent role for Nup358 in HIV-1 infection. PLoS Pathog. 2014;10:e1003969.

127. Fernandez J, Machado AK, Lyonnais S, Chamontin C, Gärtner K, Léger T, Henriquet C, Garcia C, Portilho DM, Pugnière M, et al. Transportin-1 binds to the HIV-1 capsid via a nuclear localization signal and triggers uncoating. Nat Microbiol. 2019:4:1840-50.

128. Luo X, Yang W, Gao G. SUN1 regulates HIV-1 nuclear import in a manner dependent on the interaction between the viral capsid and cellular cyclophilin A. J Virol. 2018;92.

129. Lahaye X, Satoh T, Gentili M, Cerboni S, Silvin A, Conrad C, AhmedBelkacem A, Rodriguez EC, Guichou J-F, Bosquet N, et al. Nuclear envelope protein SUN2 promotes cyclophilin-A-dependent steps of HIV replication. Cell Rep. 2016;15:879-92.

130. Dutrieux J, Maarifi G, Portilho DM, Arhel NJ, Chelbi-Alix MK, Nisole S. PML/TRIM19-dependent inhibition of retroviral reverse-transcription by Daxx. PLoS Pathog. 2015;11:e1005280.

131. Maillet S, Fernandez J, Decourcelle M, El Koulali K, Blanchet FP, Arhel NJ, Maarifi G, Nisole S. Daxx inhibits HIV-1 reverse transcription and uncoating in a SUMO-dependent manner. Viruses. 2020;12:636.

132. Lahaye X, Satoh T, Gentili M, Cerboni S, Conrad C, Hurbain I, El Marjou A, Lacabaratz C, Lelièvre J-D, Manel N. The capsids of HIV-1 and HIV-2 determine immune detection of the viral cDNA by the innate sensor cGAS in dendritic cells. Immunity. 2013;39:1132-42.

133. Rasaiyaah J, Tan CP, Fletcher AJ, Price AJ, Blondeau C, Hilditch L, Jacques DA, Selwood DL, James LC, Noursadeghi M, Towers GJ. HIV-1 evades innate immune recognition through specific cofactor recruitment. Nature. 2013:503:402-5.

134. Wei W, Guo H, Ma M, Markham R, Yu X-F. Accumulation of MxB/Mx2resistant HIV-1 capsid variants during expansion of the HIV-1 epidemic in human populations. EBioMedicine. 2016;8:230-6.

135. Setiawan LC, van Dort KA, Rits MAN, Kootstra NA. Mutations in CypA binding region of HIV-1 capsid affect capsid stability and viral replication in primary macrophages. AIDS Res Hum Retroviruses. 2016:32:390-8.

136. Saha B, Chisholm D, Kell AM, Mandell MA. A non-canonical role for the autophagy machinery in anti-retroviral signaling mediated by TRIM5alpha. PLoS Pathog. 2020;16:e1009017.

137. Manel N, Hogstad B, Wang Y, Levy DE, Unutmaz D, Littman DR. A cryptic sensor for HIV-1 activates antiviral innate immunity in dendritic cells. Nature. 2010;467:214-7.

138. Bulli L, Apolonia L, Kutzner J, Pollpeter D, Goujon C, Herold N, Schwarz S-M, Giernat Y, Keppler OT, Malim MH, Schaller T. Complex interplay between HIV-1 capsid and MX2-independent alpha interferon-induced antiviral factors. J Virol. 2016;90:7469-80.

139. Sultana T, Mamede JI, Saito A, Ode H, Nohata K, Cohen R, Nakayama EE, Iwatani Y, Yamashita M, Hope TJ, Shioda T. Multiple pathways to avoid beta interferon sensitivity of HIV-1 by mutations in capsid. J Virol. 2019;93.

140. Aberham C, Weber S, Phares W. Spontaneous mutations in the human immunodeficiency virus type $1 \mathrm{gag}$ gene that affect viral replication in the presence of cyclosporins. J Virol. 1996;70:3536-44.

141. Qi M, Yang R, Aiken C. Cyclophilin A-dependent restriction of human immunodeficiency virus type 1 capsid mutants for infection of nondividing cells. J Virol. 2008;82:12001-8.

142. Yamashita M, Emerman M. Cellular restriction targeting viral capsids perturbs human immunodeficiency virus type 1 infection of nondivid ing cells. J Virol. 2009;83:9835-43.

143. Ylinen LMJ, Schaller T, Price A, Fletcher AJ, Noursadeghi M, James LC, Towers GJ. Cyclophilin A levels dictate infection efficiency of human immunodeficiency virus type 1 capsid escape mutants A92E and G94D. J Virol. 2009:83:2044-7.

144. Yang $R$, Aiken C. A mutation in alpha helix 3 of CA renders human immunodeficiency virus type 1 cyclosporin A resistant and dependent: rescue by a second-site substitution in a distal region of CA. J Virol. 2007;81:3749-56.

145. Takemura T, Kawamata M, Urabe M, Murakami T. Cyclophilin A-dependent restriction to capsid $\mathrm{N} 121 \mathrm{~K}$ mutant human immunodeficiency virus type 1 in a broad range of cell lines. J Virol. 2013;87:4086-90.

146. Schneidewind A, Brockman MA, Yang R, Adam RI, Li B, Le Gall S, Rinaldo $C R$, Craggs SL, Allgaier RL, Power KA, et al. Escape from the dominant HLA-B27-restricted cytotoxic T-lymphocyte response in Gag is associated with a dramatic reduction in human immunodeficiency virus type 1 replication. J Virol. 2007;81:12382-93.

147. Matsuoka S, Dam E, Lecossier D, Clavel F, Hance AJ. Modulation of HIV-1 infectivity and cyclophilin A-dependence by Gag sequence and target cell type. Retrovirology. 2009;6:21.

148. Battivelli E, Lecossier D, Matsuoka S, Migraine J, Clavel F, Hance AJ. Strain-specific differences in the impact of human TRIM5alpha, different TRIM5alpha alleles, and the inhibition of capsid-cyclophilin A interactions on the infectivity of HIV-1. J Virol. 2010;84:11010-9.

149. Henning MS, Dubose BN, Burse MJ, Aiken C, Yamashita M. In vivo functions of CPSF6 for HIV-1 as revealed by HIV-1 capsid evolution in HLA-B27-positive subjects. PLoS Pathog. 2014;10:e1003868.

150. Sokolskaja E, Sayah DM, Luban J. Target cell cyclophilin A modulates human immunodeficiency virus type 1 infectivity. J Virol. 2004;78:12800-8.

151. Hatziioannou T, Perez-Caballero D, Cowan S, Bieniasz PD. Cyclophilin interactions with incoming human immunodeficiency virus type 1 capsids with opposing effects on infectivity in human cells. J Virol. 2005;79:176-83.

152. Song C, Aiken C. Analysis of human cell heterokaryons demonstrates that target cell restriction of cyclosporine-resistant human immunodeficiency virus type 1 mutants is genetically dominant. J Virol. 2007:81:11946-56.

153. De laco A, Luban J. Cyclophilin A promotes HIV-1 reverse transcription but its effect on transduction correlates best with its effect on nuclear entry of viral cDNA. Retrovirology. 2014;11:11.

154. Sokolskaja E, Berthoux L, Luban J. Cyclophilin A and TRIM5alpha independently regulate human immunodeficiency virus type 1 infectivity in human cells. J Virol. 2006;80:2855-62.

155. Zhang F, Hatziioannou T, Perez-Caballero D, Derse D, Bieniasz PD. Antiretroviral potential of human tripartite motif-5 and related proteins. Virology. 2006;353:396-409.

156. Kane M, Yadav SS, Bitzegeio J, Kutluay SB, Zang T, Wilson SJ, Schoggins JW, Rice CM, Yamashita M, Hatziioannou T, Bieniasz PD. MX2 is an interferon-induced inhibitor of HIV-1 infection. Nature. 2013;502:563-6.

157. Matreyek KA, Wang W, Serrao E, Singh PK, Levin HL, Engelman A. Host and viral determinants for MxB restriction of HIV-1 infection. Retrovirology. 2014;11:90.

158. De laco A, Luban J. Inhibition of HIV-1 infection by TNPO3 depletion is determined by capsid and detectable after viral cDNA enters the nucleus. Retrovirology. 2011;8:98.

159. Ambrose Z, Lee K, Ndjomou J, Xu H, Oztop I, Matous J, Takemura T, Unutmaz D, Engelman A, Hughes SH, KewalRamani VN. Human immunodeficiency virus type 1 capsid mutation N74D alters cyclophilin A dependence and impairs macrophage infection. J Virol. 2012;86:4708-14.

160. Shah VB, Aiken C. Gene expression analysis of a panel of cell lines that differentially restrict HIV-1 CA mutants infection in a cyclophilin a-dependent manner. PLoS ONE. 2014;9:e92724.

161. Kootstra NA, Navis M, Beugeling C, van Dort KA, Schuitemaker H. The presence of the Trim5alpha escape mutation H87Q in the capsid of late stage HIV-1 variants is preceded by a prolonged asymptomatic infection phase. AIDS (London, England). 2007;21:2015-23.

162. Brockman MA, Schneidewind A, Lahaie M, Schmidt A, Miura T, Desouza I, Ryvkin F, Derdeyn CA, Allen S, Hunter E, et al. Escape and compensation from early HLA-B57-mediated cytotoxic T-lymphocyte pressure on human immunodeficiency virus type $1 \mathrm{Gag}$ alter capsid interactions with cyclophilin A. J Virol. 2007:81:12608-18.

163. Gatanaga H, Das D, Suzuki Y, Yeh DD, Hussain KA, Ghosh AK, Mitsuya H. Altered HIV-1 Gag protein interactions with cyclophilin A (CypA) on the acquisition of $\mathrm{H} 219 \mathrm{Q}$ and $\mathrm{H} 219 \mathrm{P}$ substitutions in the CypA binding loop. J Biol Chem. 2006;281:1241-50. 
164. Ikeda Y, Ylinen LMJ, Kahar-Bador M, Towers GJ. Influence of gag on human immunodeficiency virus type 1 species-specific tropism. J Virol. 2004;78:11816-22.

165. Chatterji U, Bobardt MD, Stanfield R, Ptak RG, Pallansch LA, Ward PA, Jones MJ, Stoddart CA, Scalfaro P, Dumont J-M, et al. Naturally occurring capsid substitutions render HIV-1 cyclophilin A independent in human cells and TRIM-cyclophilin-resistant in Owl monkey cells. J Biol Chem. 2005;280:40293-300.

166. Ptak RG, Gallay PA, Jochmans D, Halestrap AP, Ruegg UT, Pallansch LA, Bobardt MD, de Béthune M-P, Neyts J, De Clercq E, et al. Inhibition of human immunodeficiency virus type 1 replication in human cells by Debio-025, a novel cyclophilin binding agent. Antimicrob Agents Chemother. 2008;52:1302-17.

167. Gallay PA, Ptak RG, Bobardt MD, Dumont J-M, Vuagniaux G, Rosenwirth B. Correlation of naturally occurring HIV-1 resistance to DEB025 with capsid amino acid polymorphisms. Viruses. 2013;5:981-97.

168. Kumar S, Morrison JH, Dingli D, Poeschla E. HIV-1 activation of innate immunity depends strongly on the intracellular level of TREX 1 and sensing of incomplete reverse transcription products. J Virol. 2018;92.

169. Sumner RP, Harrison L, Touizer E, Peacock TP, Spencer M, Zuliani-Alvarez L, Towers GJ. Disrupting HIV-1 capsid formation causes cGAS sensing of viral DNA. EMBO J. 2020;39:e103958.

170. Miles RJ, Kerridge C, Hilditch L, Monit C, Jacques DA, Towers GJ. MxB sensitivity of HIV-1 is determined by a highly variable and dynamic capsid surface. eLife. 2020;9.

171. Braaten D, Franke EK, Luban J. Cyclophilin A is required for the replication of group M human immunodeficiency virus type 1 (HIV-1) and simian immunodeficiency virus SIV(CPZ)GAB but not group O HIV-1 or other primate immunodeficiency viruses. J Virol. 1996;70:4220-7.

172. Wiegers K, Kräusslich H-G. Differential dependence of the infectivity of HIV-1 group O isolates on the cellular protein cyclophilin A. Virology. 2002;294:289-95.

173. Rits MAN, van Dort KA, Münk C, Meijer AB, Kootstra NA. Efficient transduction of simian cells by HIV-1-based lentiviral vectors that contain mutations in the capsid protein. Mol Ther J Am Soc Gene Ther. 2007;15:930-7.

174. Billich A, Hammerschmid F, Peichl P, Wenger R, Zenke G, Quesniaux V, Rosenwirth B. Mode of action of SDZ NIM 811, a nonimmunosuppressive cyclosporin A analog with activity against human immunodeficiency virus (HIV) type 1: interference with HIV protein-cyclophilin A interactions. J Virol. 1995;69:2451-61.

175. Daelemans D, Dumont J-M, Rosenwirth B, De Clercq E, Pannecouque C. Debio-025 inhibits HIV-1 by interfering with an early event in the replication cycle. Antiviral Res. 2010;85:418-21.

176. Mamede Jl, Damond F, Bernardo Ad, Matheron S, Descamps D, Battini $J$-L, Sitbon M, Courgnaud V. Cyclophilins and nucleoporins are required for infection mediated by capsids from circulating HIV-2 primary isolates. Sci Rep. 2017;7:45214.

177. Thali M, Bukovsky A, Kondo E, Rosenwirth B, Walsh CT, Sodroski J, Göttlinger HG. Functional association of cyclophilin A with HIV-1 virions. Nature. 1994;372:363-5.

178. Dorfman T, Göttlinger HG. The human immunodeficiency virus type 1 capsid p2 domain confers sensitivity to the cyclophilin-binding drug SDZ NIM 811. J Virol. 1996;70:5751-7.

179. Diaz-Griffero F, Vandegraaff N, Li Y, McGee-Estrada K, Stremlau M, Welikala S, Si Z, Engelman A, Sodroski J. Requirements for capsid-binding and an effector function in TRIMCyp-mediated restriction of HIV-1. Virology. 2006;351:404-19.

180. Lin T-Y, Emerman M. Cyclophilin A interacts with diverse lentiviral capsids. Retrovirology. 2006;3:70

181. Schaller T, Ylinen LMJ, Webb BLJ, Singh S, Towers GJ. Fusion of cyclophilin A to Fv1 enables cyclosporine-sensitive restriction of human and feline immunodeficiency viruses. J Virol. 2007;81:10055-63.

182. Kratovac Z, Virgen CA, Bibollet-Ruche F, Hahn BH, Bieniasz PD, Hatziioannou T. Primate lentivirus capsid sensitivity to TRIM5 proteins. J Virol. 2008:82:6772-7.

183. Neagu MR, Ziegler P, Pertel T, Strambio-De-Castillia C, Grütter C, Martinetti G, Mazzucchelli L, Grütter M, Manz MG, Luban J. Potent inhibition of HIV-1 by TRIM5-cyclophilin fusion proteins engineered from human components. J Clin Investig. 2009;119:3035-47.
184. Mamede Jl, Sitbon M, Battini J-L, Courgnaud V. Heterogeneous susceptibility of circulating SIV isolate capsids to HIV-interacting factors. Retrovirology. 2013;10:77.

185. Bichel K, Price AJ, Schaller T, Towers GJ, Freund SMV, James LC. HIV-1 capsid undergoes coupled binding and isomerization by the nuclear pore protein NUP358. Retrovirology. 2013;10:81.

186. Meyerson NR, Warren CJ, Vieira DASA, Diaz-Griferro F, Sawyer SL. Species-specific vulnerability of RanBP2 shaped the evolution of SIV as it transmitted in African apes. PLoS Pathog. 2018;14:e1006906.

187. Price AJ, Fletcher AJ, Schaller T, Elliott T, Lee K, KewalRamani VN, Chin JW, Towers GJ, James LC. CPSF6 defines a conserved capsid interface that modulates HIV-1 replication. PLoS Pathog. 2012;8:e1002896.

188. Price AJ, Jacques DA, McEwan WA, Fletcher AJ, Essig S, Chin JW, Halambage UD, Aiken C, James LC. Host cofactors and pharmacologic ligands share an essential interface in HIV-1 capsid that is lost upon disassembly. PLoS Pathog. 2014;10:e1004459.

189. Bhattacharya A, Alam SL, Fricke T, Zadrozny K, Sedzicki J, Taylor AB, Demeler B, Pornillos O, Ganser-Pornillos BK, Diaz-Griffero F, et al. Structural basis of HIV-1 capsid recognition by PF74 and CPSF6. Proc Natl Acad Sci USA. 2014;111:18625-30.

190. Rebensburg SV, Wei G, Larue RC, Lindenberger J, Francis AC, Annamalai AS, Morrison J, Shkriabai N, Huang S-W, KewalRamani V, et al. Sec24C is an HIV-1 host dependency factor crucial for virus replication. Nat Microbiol. 2021;6:435-44.

191. De laco A, Santoni F, Vannier A, Guipponi M, Antonarakis S, Luban J. TNPO3 protects HIV-1 replication from CPSF6-mediated capsid stabilization in the host cell cytoplasm. Retrovirology. 2013;10:20.

192. Fricke T, Brandariz-Nuñez A, Wang X, Smith AB, Diaz-Griffero F. Human cytosolic extracts stabilize the HIV-1 core. J Virol. 2013;87:10587-97.

193. Ning J, Zhong Z, Fischer DK, Harris G, Watkins SC, Ambrose Z, Zhang P. Truncated CPSF6 forms higher-order complexes that bind and disrupt HIV-1 Capsid. J Virol. 2018;92.

194. Burdick RC, Li C, Munshi M, Rawson JMO, Nagashima K, Hu W-S, Pathak VK. HIV-1 uncoats in the nucleus near sites of integration. Proc Natl Acad Sci USA. 2020;117:5486-93.

195. Di Nunzio F, Fricke T, Miccio A, Valle-Casuso JC, Perez P, Souque P, Rizzi E, Severgnini M, Mavilio F, Charneau P, Diaz-Griffero F. Nup153 and Nup98 bind the HIV-1 core and contribute to the early steps of HIV-1 replication. Virology. 2013;440:8-18.

196. Xie L, Chen L, Zhong C, Yu T, Ju Z, Wang M, Xiong H, Zeng Y, Wang J, $\mathrm{Hu} H$, et al. MxB impedes the NUP358-mediated HIV-1 pre-integration complex nuclear import and viral replication cooperatively with CPSF6. Retrovirology. 2020;17:16.

197. Buffone C, Martinez-Lopez A, Fricke T, Opp S, Severgnini M, Cifola I, Petiti L, Frabetti S, Skorupka K, Zadrozny KK, et al. Nup153 unlocks the nuclear pore complex for HIV-1 nuclear translocation in nondividing cells. J Virol. 2018;92.

198. Zhou J, Price AJ, Halambage UD, James LC, Aiken C. HIV-1 resistance to the capsid-targeting inhibitor PF74 results in altered dependence on host factors required for virus nuclear entry. J Virol. 2015;89:9068-79.

199. Saito A, Henning MS, Serrao E, Dubose BN, Teng S, Huang J, Li X, Saito N Roy SP, Siddiqui MA, et al. Capsid-CPSF6 interaction is dispensable for HIV-1 replication in primary cells but is selected during virus passage in vivo. J Virol. 2016;90:6918-35.

200. Stultz RD, Cenker JJ, McDonald D. Imaging HIV-1 genomic DNA from entry through productive infection. J Virol. 2017;91.

201. Bejarano DA, Peng K, Laketa V, Börner K, Jost KL, Lucic B, Glass B, Lusic M, Müller B, Kräusslich H-G. HIV-1 nuclear import in macrophages is regulated by CPSF6-capsid interactions at the nuclear pore complex. eLife. 2019:8.

202. Elsner C, Ponnurangam A, Kazmierski J, Zillinger T, Jansen J, Todt D, Dohner K, Xu S, Ducroux A, Kriedemann N, et al. Absence of cGASmediated type I IFN responses in HIV-1-infected T cells. Proc Natl Acad Sci USA. 2020:117:19475-86.

203. Blanco-Rodriguez G, Gazi A, Monel B, Frabetti S, Scoca V, Mueller F, Schwartz O, Krijnse-Locker J, Charneau P, Di Nunzio F. Remodeling of the core leads HIV-1 preintegration complex into the nucleus of human Iymphocytes. J Virol. 2020;94.

204. Dharan A, Bachmann N, Talley S, Zwikelmaier V, Campbell EM. Nuclear pore blockade reveals that HIV-1 completes reverse transcription and uncoating in the nucleus. Nat Microbiol. 2020;5:1088-95. 
205. Francis AC, Marin M, Prellberg MJ, Palermino-Rowland K, Melikyan GB. HIV-1 uncoating and nuclear import precede the completion of reverse transcription in cell lines and in primary macrophages. Viruses 2020;12.

206. Selyutina A, Persaud M, Lee K, Kewal Ramani V, Diaz-Griffero F. Nuclear import of the HIV-1 core precedes reverse transcription and uncoating. Cell Rep. 2020;32:108201.

207. Li C, Burdick RC, Nagashima K, Hu W-S, Pathak VK. HIV-1 cores retain their integrity until minutes before uncoating in the nucleus. Proc Nat Acad Sci USA. 2021;118:e2019467118.

208. Zila V, Margiotta E, Turoňová B, Müller TG, Zimmerli CE, Mattei S, Allegretti M, Börner K, Rada J, Müller B, et al. Cone-shaped HIV-1 capsids are transported through intact nuclear pores. Cell. 2021;28:1016.

209. Chin CR, Perreira JM, Savidis G, Portmann JM, Aker AM, Feeley EM, Smith MC, Brass AL. Direct visualization of HIV-1 replication intermediates shows that capsid and CPSF6 modulate HIV-1 intra-nuclear invasion and integration. Cell Rep. 2015;13:1717-31.

210. Chen N-Y, Zhou L, Gane PJ, Opp S, Ball NJ, Nicastro G, Zufferey M, Buffone C, Luban J, Selwood D, et al. HIV-1 capsid is involved in postnuclear entry steps. Retrovirology. 2016;13:28.

211. Sowd GA, Serrao E, Wang H, Wang W, Fadel HJ, Poeschla EM, Engelman AN. A critical role for alternative polyadenylation factor CPSF6 in targeting HIV-1 integration to transcriptionally active chromatin. Proc Natl Acad Sci USA. 2016;113:E1054-1063.

212. Francis AC, Marin M, Singh PK, Achuthan V, Prellberg MJ, PalerminoRowland K, Lan S, Tedbury PR, Sarafianos SG, Engelman AN, Melikyan GB. HIV-1 replication complexes accumulate in nuclear speckles and integrate into speckle-associated genomic domains. Nat Commun. 2020;11:3505.

213. Li W, Singh PK, Sowd GA, Bedwell GJ, Jang S, Achuthan V, Oleru AV, Wong D, Fadel HJ, Lee K, et al. CPSF6-dependent targeting of speckleassociated domains distinguishes primate from nonprimate lentiviral integration. mBio 2020;11.

214. Koh Y, Wu X, Ferris AL, Matreyek KA, Smith SJ, Lee K, KewalRamani VN, Hughes SH, Engelman A. Differential effects of human immunodeficiency virus type 1 capsid and cellular factors nucleoporin 153 and LEDGF/p75 on the efficiency and specificity of viral DNA integration. J Virol. 2013;87:648-58.

215. Dahabieh MS, Ooms M, Brumme C, Taylor J, Harrigan PR, Simon V, Sadowski I. Direct non-productive HIV-1 infection in a T-cell line is driven by cellular activation state and NFKB. Retrovirology. 2014;11:17.

216. Hatziioannou T, Princiotta M, Piatak M Jr, Yuan F, Zhang F, Lifson JD, Bieniasz PD. Generation of simian-tropic HIV-1 by restriction factor evasion. Science. 2006;314:95.

217. Zila V, Müller TG, Laketa V, Müller B, Kräusslich H-G. Analysis of CA content and CPSF6 dependence of early HIV-1 replication complexes in SupT1-R5 cells. mBio. 2019;10.

218. Achuthan V, Perreira JM, Sowd GA, Puray-Chavez M, McDougall WM, Paulucci-Holthauzen A, Wu X, Fadel HJ, Poeschla EM, Multani AS, et al. Capsid-CPSF6 interaction licenses nuclear HIV-1 trafficking to sites of viral DNA integration. Cell Host Microbe. 2018;24:392-404.e398.

219. Ohainle M, Kim K, Komurlu Keceli S, Felton A, Campbell E, Luban J, Emerman M. TRIM34 restricts HIV-1 and SIV capsids in a TRIM5adependent manner. PLoS Pathog. 2020;16:e1008507.

220. Fischer DK, Saito A, Kline C, Cohen R, Watkins SC, Yamashita M, Ambrose Z. CA mutation N57A has distinct strain-specific HIV-1 capsid uncoating and infectivity phenotypes. J Virol. 2019;93.

221. Saito A, Sultana T, Ode H, Nohata K, Samune Y, Nakayama EE, Iwatani Y, Shioda T. The 4th and 112th residues of viral capsid cooperatively modulate capsid-CPSF6 interactions of HIV-1. AIDS Res Hum Retroviruses. 2020;36:513-21.

222. Zhou L, Sokolskaja E, Jolly C, James W, Cowley SA, Fassati A. Transportin 3 promotes a nuclear maturation step required for efficient HIV-1 integration. PLoS Pathog. 2011;7:e1002194.

223. Blair WS, Pickford C, Irving SL, Brown DG, Anderson M, Bazin R, Cao J, Ciaramella G, Isaacson J, Jackson L, et al. HIV capsid is a tractable target for small molecule therapeutic intervention. PLoS Pathog. 2010;6:e1001220.

224. Vozzolo L, Loh B, Gane PJ, Tribak M, Zhou L, Anderson I, Nyakatura E, Jenner RG, Selwood D, Fassati A. Gyrase B inhibitor impairs HIV-1 replication by targeting $\mathrm{Hsp} 90$ and the capsid protein. J Biol Chem. 2010;285:39314-28.
225. Lamorte L, Titolo S, Lemke CT, Goudreau N, Mercier J-F, Wardrop E, Shah VB, von Schwedler UK, Langelier C, Banik SSR, et al. Discovery of novel small-molecule HIV-1 replication inhibitors that stabilize capsid complexes. Antimicrob Agents Chemother. 2013;57:4622-31.

226. Saito A, Ode H, Nohata K, Ohmori H, Nakayama EE, Iwatani Y, Shioda T. HIV-1 is more dependent on the K182 capsid residue than HIV-2 for interactions with CPSF6. Virology. 2019;532:118-26.

227. Fricke T, Valle-Casuso JC, White TE, Brandariz-Nuñez A, Bosche WJ, Reszka N, Gorelick R, Diaz-Griffero F. The ability of TNPO3-depleted cells to inhibit HIV-1 infection requires CPSF6. Retrovirology. 2013;10:46.

228. Keckesova Z, Ylinen LMJ, Towers GJ. The human and African green monkey TRIM5alpha genes encode Ref1 and LV1 retroviral restriction factor activities. Proc Natl Acad Sci USA. 2004;101:10780-5.

229. Hatziioannou T, Perez-Caballero D, Yang A, Cowan S, Bieniasz PD. Retrovirus resistance factors Ref1 and LV1 are species-specific variants of TRIM5alpha. Proc Natl Acad Sci USA. 2004;101:10774-9.

230. Stremlau M, Owens CM, Perron MJ, Kiessling M, Autissier P, Sodroski J. The cytoplasmic body component TRIM5alpha restricts HIV-1 infection in Old World monkeys. Nature. 2004;427:848-53.

231. Yap MW, Nisole S, Lynch C, Stoye JP. Trim5alpha protein restricts both HIV-1 and murine leukemia virus. Proc Natl Acad Sci USA. 2004;101:10786-91.

232. Nisole S, Lynch C, Stoye JP, Yap MW. A Trim5-cyclophilin A fusion protein found in owl monkey kidney cells can restrict HIV-1. Proc Natl Acad Sci USA. 2004;101:13324-8.

233. Sayah DM, Sokolskaja E, Berthoux L, Luban J. Cyclophilin A retrotransposition into TRIM5 explains owl monkey resistance to HIV-1. Nature. 2004;430:569-73.

234. Sawyer SL, Wu LI, Emerman M, Malik HS. Positive selection of primate TRIM5alpha identifies a critical species-specific retroviral restriction domain. Proc Natl Acad Sci USA. 2005;102:2832-7.

235. Towers GJ. The control of viral infection by tripartite motif proteins and cyclophilin A. Retrovirology. 2007;4:40.

236. Blanco-Melo D, Venkatesh S, Bieniasz PD. Intrinsic cellular defenses against human immunodeficiency viruses. Immunity. 2012;37:399-411.

237. Sanz-Ramos M, Stoye JP. Capsid-binding retrovirus restriction factors: discovery, restriction specificity and implications for the development of novel therapeutics. J Gen Virol. 2013;94:2587-98.

238. Ganser-Pornillos BK, Pornillos O. Restriction of HIV-1 and other retroviruses by TRIM5. Nat Rev Microbiol. 2019;17:546-56.

239. Luban J. Cyclophilin A, TRIM5, and resistance to human immunodeficiency virus type 1 infection. J Virol. 2007;81:1054-61.

240. Hatziioannou T, Cowan S, Von Schwedler UK, Sundquist WI, Bieniasz PD. Species-specific tropism determinants in the human immunodeficiency virus type 1 capsid. J Virol. 2004;78:6005-12.

241. Kamada K, Igarashi T, Martin MA, Khamsri B, Hatcho K, Yamashita T, Fujita M, Uchiyama T, Adachi A. Generation of HIV-1 derivatives that productively infect macaque monkey lymphoid cells. Proc Natl Acad Sci USA. 2006;103:16959-64.

242. Owens CM, Song B, Perron MJ, Yang PC, Stremlau M, Sodroski J. Binding and susceptibility to postentry restriction factors in monkey cells are specified by distinct regions of the human immunodeficiency virus type 1 capsid. J Virol. 2004;78:5423-37.

243. Soll SJ, Wilson SJ, Kutluay SB, Hatziioannou T, Bieniasz PD. Assisted evolution enables HIV-1 to overcome a high TRIM5a-imposed genetic barrier to rhesus macaque tropism. PLoS Pathog. 2013;9:e1003667.

244. Kootstra NA, Munk C, Tonnu N, Landau NR, Verma IM. Abrogation of postentry restriction of HIV-1-based lentiviral vector transduction in simian cells. Proc Natl Acad Sci USA. 2003;100:1298-303.

245. Pacheco B, Finzi A, Stremlau M, Sodroski J. Adaptation of HIV-1 to cells expressing rhesus monkey TRIM5a. Virology. 2010;408:204-12.

246. Setiawan LC, Kootstra NA. Adaptation of HIV-1 to rhTrim5a-mediated restriction in vitro. Virology. 2015;486:239-47.

247. Nomaguchi M, Yokoyama M, Kono K, Nakayama EE, Shioda T, Doi N, Fujiwara S, Saito A, Akari H, Miyakawa K, et al. Generation of rhesus macaque-tropic HIV-1 clones that are resistant to major anti-HIV-1 restriction factors. J Virol. 2013;87:11447-61.

248. Nomaguchi M, Yokoyama M, Kono K, Nakayama EE, Shioda T, Saito A, Akari H, Yasutomi Y, Matano T, Sato H, Adachi A. Gag-CA Q110D mutation elicits TRIM5-independent enhancement of HIV-1 mt replication in macaque cells. Microbes Infect. 2013;15:56-65. 
249. Kono K, Song H, Yokoyama M, Sato H, Shioda T, Nakayama EE. Multiple sites in the $\mathrm{N}$-terminal half of simian immunodeficiency virus capsid protein contribute to evasion from rhesus monkey TRIM5a-mediated restriction. Retrovirology. 2010;7:72.

250. Ohkura S, Goldstone DC, Yap MW, Holden-Dye K, Taylor IA, Stoye JP. Novel escape mutants suggest an extensive TRIM5a binding site spanning the entire outer surface of the murine leukemia virus capsid protein. PLoS Pathog. 2011;7:e1002011.

251. McCarthy KR, Schmidt AG, Kirmaier A, Wyand AL, Newman RM, Johnson WE. Gain-of-sensitivity mutations in a Trim5-resistant primary isolate of pathogenic SIV identify two independent conserved determinants of Trim5a specificity. PLoS Pathog. 2013;9:e1003352.

252. Kuroishi A, Saito A, Shingai Y, Shioda T, Nomaguchi M, Adachi A, Akari H, Nakayama EE. Modification of a loop sequence between alpha-helices 6 and 7 of virus capsid (CA) protein in a human immunodeficiency virus type 1 (HIV-1) derivative that has simian immunodeficiency virus (SIVmac239) vif and CA alpha-helices 4 and 5 loop improves replication in cynomolgus monkey cells. Retrovirology. 2009;6:70.

253. Kuroishi A, Bozek K, Shioda T, Nakayama EE. A single amino acid substitution of the human immunodeficiency virus type 1 capsid protein affects viral sensitivity to TRIM5 alpha. Retrovirology. 2010;7:58.

254. Ganser-Pornillos BK, Chandrasekaran V, Pornillos O, Sodroski JG, Sundquist WI, Yeager M. Hexagonal assembly of a restricting TRIM5alpha protein. Proc Natl Acad Sci USA. 2011;108:534-9.

255. Biris N, Yang Y, Taylor AB, Tomashevski A, Guo M, Hart PJ, Diaz-Griffero F, Ivanov DN. Structure of the rhesus monkey TRIM5a PRYSPRY domain, the HIV capsid recognition module. Proc Natl Acad Sci USA. 2012;109:13278-83.

256. Biris N, Tomashevski A, Bhattacharya A, Diaz-Griffero F, Ivanov DN. Rhesus monkey TRIM5a SPRY domain recognizes multiple epitopes that span several capsid monomers on the surface of the HIV-1 mature viral core. J Mol Biol. 2013:425:5032-44.

257. Yang H, Ji X, Zhao G, Ning J, Zhao Q, Aiken C, Gronenborn AM, Zhang $\mathrm{P}$, Xiong Y. Structural insight into HIV-1 capsid recognition by rhesus TRIM5a. Proc Natl Acad Sci USA. 2012;109:18372-7.

258. Goldstone DC, Walker PA, Calder LJ, Coombs PJ, Kirkpatrick J, Ball NJ, Hilditch L, Yap MW, Rosenthal PB, Stoye JP, Taylor IA. Structural studies of postentry restriction factors reveal antiparallel dimers that enable avid binding to the HIV-1 capsid lattice. Proc Natl Acad Sci USA. 2014;111:9609-14.

259. Li Y-L, Chandrasekaran V, Carter SD, Woodward CL, Christensen DE, Dryden KA, Pornillos O, Yeager M, Ganser-Pornillos BK, Jensen GJ, Sundquist WI. Primate TRIM5 proteins form hexagonal nets on HIV-1 capsids. eLife. 2016;5

260. Morger D, Zosel F, Bühlmann M, Züger S, Mittelviefhaus M, Schuler B, Luban J, Grütter MG. The three-fold axis of the HIV-1 capsid lattice is the species-specific binding interface for TRIM5a. JVirol. 2018;92.

261. Summers BJ, Digianantonio KM, Smaga SS, Huang P-T, Zhou K, Gerber EE, Wang W, Xiong Y. Modular HIV-1 capsid assemblies reveal diverse host-capsid recognition mechanisms. Cell Host Microbe. 2019;26:203216.e206.

262. Hatziioannou T, Evans DT. Animal models for HIV/AIDS research. Nat Rev Microbiol. 2012;10:852-67.

263. Thippeshappa R, Kimata JT, Kaushal D. Toward a macaque model of HIV-1 infection: roadblocks, progress, and future strategies. Front Microbiol. 2020;11:882.

264. Nomaguchi M, Nakayama EE, Yokoyama M, Doi N, Igarashi T, Shioda T, Sato H, Adachi A. Distinct combinations of amino acid substitutions in N-terminal domain of Gag-capsid afford HIV-1 resistance to rhesus TRIM5a. Microbes Infect. 2014;16:936-44.

265. Liao C-H, Kuang Y-Q, Liu H-L, Zheng Y-T, Su B. A novel fusion gene, TRIM5-Cyclophilin A in the pig-tailed macaque determines its susceptibility to HIV-1 infection. AIDS (London, England). 2007;21(Suppl 8):S19-26.

266. Brennan G, Kozyrev Y, Hu S-L. TRIMCyp expression in Old World primates Macaca nemestrina and Macaca fascicularis. Proc Natl Acad Sci USA. 2008;105:3569-74.

267. Newman RM, Hall L, Kirmaier A, Pozzi L-A, Pery E, Farzan M, O'Neil SP, Johnson W. Evolution of a TRIM5-CypA splice isoform in old world monkeys. PLoS Pathog. 2008;4:e1000003.
268. Virgen CA, Kratovac Z, Bieniasz PD, Hatziioannou T. Independent genesis of chimeric TRIM5-cyclophilin proteins in two primate species. Proc Natl Acad Sci USA. 2008;105:3563-8

269. Wilson SJ, Webb BLJ, Ylinen LMJ, Verschoor E, Heeney JL, Towers GJ. Independent evolution of an antiviral TRIMCyp in rhesus macaques. Proc Natl Acad Sci USA. 2008;105:3557-62.

270. Towers GJ, Hatziioannou T, Cowan S, Goff SP, Luban J, Bieniasz PD. Cyclophilin A modulates the sensitivity of HIV-1 to host restriction factors. Nat Med. 2003:9:1138-43.

271. Dietrich EA, Brennan G, Ferguson B, Wiseman RW, O'Connor D, Hu S-L. Variable prevalence and functional diversity of the antiretroviral restriction factor TRIMCyp in Macaca fascicularis. J Virol. 2011;85:9956-63.

272. Saito A, Kono K, Nomaguchi M, Yasutomi Y, Adachi A, Shioda T, Akari $\mathrm{H}$, Nakayama EE. Geographical, genetic and functional diversity of antiretroviral host factor TRIMCyp in cynomolgus macaque (Macaca fascicularis). J Gen Virol. 2012;93:594-602.

273. Saito A, Kawamoto Y, Higashino A, Yoshida T, Ikoma T, Suzaki Y, Ami Y, Shioda T, Nakayama EE, Akari H. Allele frequency of antiretroviral host factor TRIMCyp in wild-caught cynomolgus macaques (Macaca fascicularis). Front Microbiol. 2012;3:314.

274. Price AJ, Marzetta F, Lammers M, Ylinen LMJ, Schaller T, Wilson SJ, Towers GJ, James LC. Active site remodeling switches HIV specificity of antiretroviral TRIMCyp. Nat Struct Mol Biol. 2009;16:1036-42.

275. Sultana T, Nakayama EE, Tobita S, Yokoyama M, Seki Y, Saito A, Nomaguchi M, Adachi A, Akari H, Sato H, Shioda T. Novel mutant human immunodeficiency virus type 1 strains with high degree of resistance to cynomolgus macaque TRIMCyp generated by random mutagenesis. J Gen Virol. 2016;97:963-76.

276. Kirmaier A, Krupp A, Johnson WE. Understanding restriction factors and intrinsic immunity: insights and lessons from the primate lentiviruses. Futur Virol. 2014:9:483-97.

277. Kirmaier A, Wu F, Newman RM, Hall LR, Morgan JS, O'Connor S, Marx PA, Meythaler M, Goldstein S, Buckler-White A, et al. TRIM5 suppresses cross-species transmission of a primate immunodeficiency virus and selects for emergence of resistant variants in the new species. PLoS Biol. 2010;8:e1000462.

278. Wu F, Kirmaier A, Goeken R, Ourmanov I, Hall L, Morgan JS, Matsuda K, Buckler-White A, Tomioka K, Plishka R, et al. TRIM5 alpha drives SIVsmm evolution in rhesus macaques. PLoS Pathog. 2013;9:e1003577.

279. Wu F, Ourmanov I, Riddick N, Matsuda K, Whitted S, Plishka RJ, BucklerWhite A, Starost MF, Hirsch VM. TRIM5a restriction affects clinical outcome and disease progression in simian immunodeficiency virusinfected rhesus macaques. J Virol. 2015;89:2233-40.

280. Wu F, Kirmaier A, White E, Ourmanov I, Whitted S, Matsuda K, Riddick N, Hall LR, Morgan JS, Plishka RJ, et al. TRIM5a resistance escape mutations in the capsid are transferable between simian immunodeficiency virus strains. J Virol. 2016;90:11087-95.

281. Battivelli E, Migraine J, Lecossier D, Yeni P, Clavel F, Hance AJ. Gag cytotoxic T lymphocyte escape mutations can increase sensitivity of HIV-1 to human TRIM5alpha, linking intrinsic and acquired immunity. J Virol. 2011:85:11846-54.

282. Granier C, Battivelli E, Lécuroux C, Venet A, Lambotte O, SchmittBoulanger M, Delaugerre C, Molina J-M, Chakrabarti LA, Clavel F, Hance AJ. Pressure from TRIM5a contributes to control of HIV-1 replication by individuals expressing protective HLA-B alleles. J Virol. 2013;87:10368-80.

283. Merindol N, El-Far M, Sylla M, Masroori N, Dufour C, Li J-X, Cherry P, Plourde MB, Tremblay C, Berthoux L. HIV-1 capsids from B27/B57+ elite controllers escape M×2 but are targeted by TRIM5a, leading to the induction of an antiviral state. PLoS Pathog. 2018;14:e1007398.

284. Ylinen LMJ, Keckesova Z, Wilson SJ, Ranasinghe S, Towers GJ. Differential restriction of human immunodeficiency virus type 2 and simian immunodeficiency virus SIVmac by TRIM5alpha alleles. J Virol. 2005:79:11580-7.

285. Takeuchi JS, Perche B, Migraine J, Mercier-Delarue S, Ponscarme D, Simon F, Clavel F, Labrosse B. High level of susceptibility to human TRIM5a conferred by HIV-2 capsid sequences. Retrovirology. 2013;10:50.

286. Onyango CO, Leligdowicz A, Yokoyama M, Sato H, Song H, Nakayama EE, Shioda T, de Silva T, Townend J, Jaye A, et al. HIV-2 capsids distinguish high and low virus load patients in a West African community cohort. Vaccine. 2010;28(Suppl 2):B60-67. 
287. Song H, Nakayama EE, Yokoyama M, Sato H, Levy JA, Shioda T. A single amino acid of the human immunodeficiency virus type 2 capsid affects its replication in the presence of cynomolgus monkey and human TRIM5alphas. J Virol. 2007;81:7280-5.

288. Miyamoto T, Yokoyama M, Kono K, Shioda T, Sato H, Nakayama EE. A single amino acid of human immunodeficiency virus type 2 capsid protein affects conformation of two external loops and viral sensitivity to TRIM5a. PLoS ONE. 2011;6:e22779.

289. Jimenez-Guardeño JM, Apolonia L, Betancor G, Malim MH. Immunoproteasome activation enables human TRIM5a restriction of HIV-1. Nat Microbiol. 2019;4:933-40.

290. OhAinle M, Helms L, Vermeire J, Roesch F, Humes D, Basom R, Delrow $\mathrm{JJ}$, Overbaugh J, Emerman M. A virus-packageable CRISPR screen identifies host factors mediating interferon inhibition of HIV. eLife. 2018;7.

291. Rahm N, Gfeller D, Snoeck J, Martinez R, McLaren PJ, Ortiz M, Ciuffi A, Telenti A. Susceptibility and adaptation to human TRIM5a alleles at positive selected sites in HIV-1 capsid. Virology. 2013;441:162-70.

292. Goujon C, Moncorgé O, Bauby H, Doyle T, Ward CC, Schaller T, Hué S, Barclay WS, Schulz R, Malim MH. Human MX2 is an interferon-induced post-entry inhibitor of HIV-1 infection. Nature. 2013;502:559-62.

293. Liu Z, Pan Q, Ding S, Qian J, Xu F, Zhou J, Cen S, Guo F, Liang C. The interferon-inducible MxB protein inhibits HIV-1 infection. Cell Host Microbe. 2013;14:398-410.

294. Busnadiego I, Kane M, Rihn SJ, Preugschas HF, Hughes J, Blanco-Melo D, Strouvelle VP, Zang TM, Willett BJ, Boutell C, et al. Host and viral determinants of Mx2 antiretroviral activity. J Virol. 2014;88:7738-52.

295. Goujon C, Moncorgé O, Bauby H, Doyle T, Barclay WS, Malim MH. Transfer of the amino-terminal nuclear envelope targeting domain of human MX2 converts MX1 into an HIV-1 resistance factor. J Virol. 2014;88:9017-26.

296. Goujon C, Greenbury RA, Papaioannou S, Doyle T, Malim MH. A triplearginine motif in the amino-terminal domain and oligomerization are required for HIV-1 inhibition by human MX2. J Virol. 2015;89:4676-80.

297. Schulte B, Buffone C, Opp S, Di Nunzio F, De Souza Aranha Vieira DA, Brandariz-Nuñez A, Diaz-Griffero F. Restriction of HIV-1 requires the $\mathrm{N}$-Terminal region of $\mathrm{M} \times \mathrm{B}$ as a capsid-binding motif but not as a nuclear localization signal. J Virol. 2015;89:8599-610.

298. Dicks MDJ, Betancor G, Jimenez-Guardeño JM, Pessel-Vivares L, Apolonia L, Goujon C, Malim MH. Multiple components of the nuclear pore complex interact with the amino-terminus of MX2 to facilitate HIV-1 restriction. PLoS Pathog. 2018;14:e1007408.

299. Fribourgh JL, Nguyen HC, Matreyek KA, Alvarez FJD, Summers BJ, Dewdney TG, Aiken C, Zhang P, Engelman A, Xiong Y. Structural insight into HIV-1 restriction by MxB. Cell Host Microbe. 2014;16:627-38.

300. Fricke T, White TE, Schulte B, de Souza Aranha Vieira DA, Dharan A, Campbell EM, Brandariz-Nuñez A, Diaz-Griffero F. MxB binds to the HIV-1 core and prevents the uncoating process of HIV-1. Retrovirology. 2014;11:68.

301. Kong J, Xu B, Wei W, Wang X, Xie W, Yu X-F. Characterization of the amino-terminal domain of M×2/MXB-dependent interaction with the HIV-1 capsid. Protein Cell. 2014:5.954-7.

302. Betancor G, Dicks MDJ, Jimenez-Guardeño JM, Ali NH, Apolonia L, Malim MH. The GTPase domain of MX2 interacts with the HIV-1 capsid, enabling its short isoform to moderate antiviral restriction. Cell Rep. 2019;29:1923-1933.e1923.

303. Smaga SS, Xu C, Summers BJ, Digianantonio KM, Perilla JR, Xiong Y. MxB restricts HIV-1 by targeting the tri-hexamer interface of the viral capsid. Structure (London, England: 1993). 2019;27:1234-1245e1235.

304. Liu Z, Pan Q, Liang Z, Qiao W, Cen S, Liang C. The highly polymorphic cyclophilin A-binding loop in HIV-1 capsid modulates viral resistance to MxB. Retrovirology. 2015;12:1.

305. Lu M, Hou G, Zhang H, Suiter CL, Ahn J, Byeon I-JL, Perilla JR, Langmead CJ, Hung I, Gorkov PL, et al. Dynamic allostery governs cyclophilin A-HIV capsid interplay. Proc Nat Acad Sci USA. 2015;112:14617-14622.

306. Schmidt F, Keele BF, Del Prete GQ, Voronin D, Fennessey CM, Soll S, Kane M, Raymond A, Gifford RJ, KewalRamani V, et al. Derivation of simian tropic HIV-1 infectious clone reveals virus adaptation to a new host. Proc Natl Acad Sci USA. 2019;116:10504-9.
307. Nakayama EE, Saito A, Sultana T, Jin Z, Nohata K, Shibata M, Hosoi M, Motomura K, Shioda T, Sangkitporn S, et al. Naturally occurring mutations in HIV-1 CRF01_AE capsid affect viral sensitivity to restriction factors. AIDS Res Hum Retroviruses. 2018;34:382-92.

308. Xu B, Pan Q, Liang C. Role of MxB in alpha interferon-mediated inhibition of HIV-1 infection. J Virol. 2018;92.

309. Opp S, Vieira DASA, Schulte B, Chanda SK, Diaz-Griffero F. MxB is not responsible for the blocking of HIV-1 infection observed in alpha interferon-treated cells. J Virol. 2015;90:3056-64.

310. Ji S, Na L, Ren H, Wang Y, Wang X. Equine myxovirus resistance protein 2 restricts lentiviral replication by blocking nuclear uptake of capsid protein. J Virol. 2018;92.

311. Meier K, Jaguva Vasudevan AA, Zhang Z, Bähr A, Kochs G, Häussinger D, Münk $C$. Equine $M X 2$ is a restriction factor of equine infectious anemia virus (EIAV). Virology. 2018;523:52-63.

312. Morrison JH, Miller C, Bankers L, Crameri G, Wang L-F, Poeschla EM. A potent postentry restriction to primate lentiviruses in a yinpterochiropteran bat. mBio. 2020;11.

313. Bähr A, Singer A, Hain A, Vasudevan AAJ, Schilling M, Reh J, Riess M, Panitz S, Serrano V, Schweizer M, et al. Interferon but not MxB inhibits foamy retroviruses. Virology. 2016;488:51-60.

314. Blair WS, Cao J, Fok-Seang J, Griffin P, Isaacson J, Jackson RL, Murray E, Patick AK, Peng Q, Perros M, et al. New small-molecule inhibitor class targeting human immunodeficiency virus type 1 virion maturation. Antimicrob Agents Chemother. 2009;53:5080-7.

315. Yant SR, Mulato A, Hansen D, Tse WC, Niedziela-Majka A, Zhang JR, Stepan GJ, Jin D, Wong MH, Perreira JM, et al. A highly potent longacting small-molecule HIV-1 capsid inhibitor with efficacy in a humanized mouse model. Nat Med. 2019;25:1377-84.

316. Link JO, Rhee MS, Tse WC, Zheng J, Somoza JR, Rowe W, Begley R, Chiu A, Mulato A, Hansen D, et al. Clinical targeting of HIV capsid protein with a long-acting small molecule. Nature. 2020;584:614-8.

317. Shi J, Zhou J, Shah VB, Aiken C, Whitby K. Small-molecule inhibition of human immunodeficiency virus type 1 infection by virus capsid destabilization. J Virol. 2011:85:542-9.

318. Fricke T, Buffone C, Opp S, Valle-Casuso J, Diaz-Griffero F. BI-2 destabilizes HIV-1 cores during infection and prevents binding of CPSF6 to the HIV-1 capsid. Retrovirology. 2014;11:120.

319. Hulme AE, Kelley Z, Foley D, Hope TJ. Complementary assays reveal a low level of CA associated with viral complexes in the nuclei of HIV1-infected cells. J Virol. 2015;89:5350-61.

320. Saito A, Ferhadian D, Sowd GA, Serrao E, Shi J, Halambage UD, Teng S, Soto J, Siddiqui MA, Engelman AN, et al. Roles of capsid-interacting host factors in multimodal inhibition of HIV-1 by PF74. J Virol. 2016;90:5808-23.

321. Balasubramaniam M, Zhou J, Addai A, Martinez P, Pandhare J, Aiken C, Dash C. PF74 inhibits HIV-1 integration by altering the composition of the preintegration complex. J Virol. 2019;93.

322. Shi J, Zhou J, Halambage UD, Shah VB, Burse MJ, Wu H, Blair WS, Butler SL, Aiken C. Compensatory substitutions in the HIV-1 capsid reduce the fitness cost associated with resistance to a capsid-targeting smallmolecule inhibitor. J Virol. 2015;89:208-19.

323. Shah VB, Shi J, Hout DR, Oztop I, Krishnan L, Ahn J, Shotwell MS, Engelman A, Aiken C. The host proteins transportin SR2/TNPO3 and cyclophilin A exert opposing effects on HIV-1 uncoating. J Virol. 2013;87:422-32.

324. Bester SM, Wei G, Zhao H, Adu-Ampratwum D, lqbal N, Courouble W, Francis AC, Annamalai AS, Singh PK, Shkriabai N, et al. Structural and mechanistic bases for a potent HIV-1 capsid inhibitor. Science (New York, NY). 2020;370:360-4.

325. McArthur C, Gallazzi F, Quinn TP, Singh K. HIV capsid inhibitors beyond PF74. Diseases. 2019;7.

326. Sun Q, Levy RM, Kirby KA, Wang Z, Sarafianos SG, Deng N. Molecular dynamics free energy simulations reveal the mechanism for the antiviral resistance of the M66I HIV-1 capsid mutation. Viruses. 2021;13.

327. Marcelin A-G, Charpentier C, Jary A, Perrier M, Margot N, Callebaut C, Calvez V, Descamps D. Frequency of capsid substitutions associated with GS-6207 in vitro resistance in HIV-1 from antiretroviral-naive and -experienced patients. J Antimicrob Chemother. 2020;75:1588-90.

328. Twizerimana AP, Scheck R, Becker D, Zhang Z, Wammers M, Avelar L, Pflieger M, Häussinger D, Kurz T, Gohlke H, Münk C. Cell 
type-dependent escape of capsid inhibitors by simian immunodeficiency virus SIVcpz. J Virol. 2020;94.

329. Lemke CT, Titolo S, von Schwedler U, Goudreau N, Mercier J-F, Wardrop E, Faucher A-M, Coulombe R, Banik SSR, Fader L, et al. Distinct effects of two HIV-1 capsid assembly inhibitor families that bind the same site within the $\mathrm{N}$-terminal domain of the viral CA protein. J Virol. 2012:86:6643-55.

330. Kleinpeter AB, Freed EO. HIV-1 maturation: lessons learned from inhibitors. Viruses. 2020:12.

331. Zhou J, Yuan X, Dismuke D, Forshey BM, Lundquist C, Lee K-H, Aiken $\mathrm{C}$, Chen CH. Small-molecule inhibition of human immunodeficiency virus type 1 replication by specific targeting of the final step of virion maturation. J Virol. 2004;78:922-9.

332. Adamson CS, Ablan SD, Boeras I, Goila-Gaur R, Soheilian F, Nagashima K, Li F, Salzwedel K, Sakalian M, Wild CT, Freed EO. In vitro resistance to the human immunodeficiency virus type 1 maturation inhibitor PA-457 (Bevirimat). J Virol. 2006;80:10957-71.

333. Adamson CS, Waki K, Ablan SD, Salzwedel K, Freed EO. Impact of human immunodeficiency virus type 1 resistance to protease inhibitors on evolution of resistance to the maturation inhibitor bevirimat (PA457). J Virol. 2009;83:4884-94.

334. Knapp DJHF, Harrigan PR, Poon AFY, Brumme ZL, Brockman M, Cheung PK. In vitro selection of clinically relevant bevirimat resistance mutations revealed by "deep" sequencing of serially passaged, quasispeciescontaining recombinant HIV-1. J Clin Microbiol. 2011;49:201-8.

335. Fun A, van Maarseveen NM, Pokorná J, Maas RE, Schipper PJ, Konvalinka J, Nijhuis M. HIV-1 protease inhibitor mutations affect the development of HIV-1 resistance to the maturation inhibitor bevirimat. Retrovirology. 2011;8:70.

336. Waki K, Durell SR, Soheilian F, Nagashima K, Butler SL, Freed EO. Structural and functional insights into the HIV-1 maturation inhibitor binding pocket. PLoS Pathog. 2012;8:e1002997.

337. Urano E, Timilsina U, Kaplan JA, Ablan S, Ghimire D, Pham P, Kuruppu N, Mandt R, Durell SR, Nitz TJ, et al. Resistance to second-generation HIV-1 maturation inhibitors. J Virol. 2019;93.

338. Dicker I, Zhang S, Ray N, Beno BR, Regueiro-Ren A, Joshi S, Cockett M, Krystal M, Lataillade M. Resistance profile of the HIV-1 maturation inhibitor GSK3532795 in vitro and in a clinical study. PLoS ONE. 2019;14:e0224076.

339. Ghimire D, Timilsina U, Srivastava TP, Gaur R. Insights into the activity of maturation inhibitor PF-46396 on HIV-1 clade C. Sci Rep. 2017;7:43711.

340. Margot NA, Gibbs CS, Miller MD. Phenotypic susceptibility to bevirimat in isolates from HIV-1-infected patients without prior exposure to bevirimat. Antimicrob Agents Chemother. 2010;54:2345-53.

341. Dharan A, Opp S, Abdel-Rahim O, Keceli SK, Imam S, Diaz-Griffero F, Campbell EM. Bicaudal D2 facilitates the cytoplasmic trafficking and nuclear import of HIV-1 genomes during infection. Proc Natl Acad Sci USA. 2017;114:E10707-16.

342. Carnes SK, Zhou J, Aiken C. HIV-1 engages a dynein-dynactin-BICD2 complex for infection and transport to the nucleus. J Virol. 2018;92.

343. Mitra S, Shanmugapriya S, Santos da Silva E, Naghavi MH. HIV-1 Exploits CLASP2 to induce microtubule stabilization and facilitate virus trafficking to the nucleus. J Virol. 2020;94.

344. Schmitz C, Marchant D, Neil SJ, Aubin K, Reuter S, Dittmar MT, McKnight A. LV2, a novel postentry restriction, is mediated by both capsid and envelope. J Virol. 2004;78:2006-16.
345. Pineda MJ, Orton BR, Overbaugh J. A TRIM5alpha-independent postentry restriction to HIV-1 infection of macaque cells that is dependent on the path of entry. Virology. 2007;363:310-8.

346. Pizzato M, McCauley SM, Neagu MR, Pertel T, Firrito C, Ziglio S, Dauphin A, Zufferey M, Berthoux L, Luban J. Lv4 is a capsid-specific antiviral activity in human blood cells that restricts viruses of the SIVMAC/SIVSM/ HIV-2 lineage prior to integration. PLoS Pathog. 2015:11:e1005050.

347. Pacheco B, Menéndez-Arias L, Sodroski J. Characterization of two distinct early post-entry blocks to HIV-1 in common marmoset lymphocytes. Sci Rep. 2016;6:37489.

348. Marno KM, O'Sullivan E, Jones CE, Diaz-Delfin J, Pardieu C, Sloan RD, McKnight A. RNA-associated early-stage antiviral factor is a major component of LV2 Restriction. JVirol. 2017;91.

349. Kinloch NN, Lee GQ, Carlson JM, Jin SW, Brumme CJ, Byakwaga H, Muzoora C, Bwana MB, Cobarrubias KD, Hunt PW, et al. Genotypic and mechanistic characterization of subtype-specific HIV adaptation to host cellular immunity. J Virol. 2019;93.

350. Araya $\mathrm{CL}$, Fowler DM. Deep mutational scanning: assessing protein function on a massive scale. Trends Biotechnol. 2011;29:435-42.

351. Robins WP, Faruque SM, Mekalanos JJ. Coupling mutagenesis and parallel deep sequencing to probe essential residues in a genome or gene. Proc Natl Acad Sci USA. 2013;110:E848-857.

352. Al-Mawsawi LQ, Wu NC, Olson CA, Shi VC, Qi H, Zheng X, Wu TT, Sun R. High-throughput profiling of point mutations across the HIV-1 genome. Retrovirology. 2014;11:124.

353. Haddox HK, Dingens AS, Hilton SK, Overbaugh J, Bloom JD. Mapping mutational effects along the evolutionary landscape of HIV envelope. Elife. 2018;7.

354. Dingens AS, Arenz D, Overbaugh J, Bloom JD. Massively parallel profiling of HIV-1 resistance to the fusion inhibitor enfuvirtide. Viruses. 2019:11.

355. Schommers P, Gruell H, Abernathy ME, Tran MK, Dingens AS, Gristick HB, Barnes CO, Schoofs T, Schlotz M, Vanshylla K, et al. Restriction of HIV-1 escape by a highly broad and potent neutralizing antibody. Cell. 2020;180:471-489e422.

356. Brass AL, Dykxhoorn DM, Benita Y, Yan N, Engelman A, Xavier RJ, Lieberman J, Elledge SJ. Identification of host proteins required for HIV infection through a functional genomic screen. Science. 2008;319:921-6.

357. Konig R, Zhou Y, Elleder D, Diamond TL, Bonamy GM, Irelan JT, Chiang CY, Tu BP, De Jesus PD, Lilley CE, et al. Global analysis of host-pathogen interactions that regulate early-stage HIV-1 replication. Cell. 2008:135:49-60.

358. Donahue DA, Amraoui S, di Nunzio F, Kieffer C, Porrot F, Opp S, DiazGriffero F, Casartelli N, Schwartz O. SUN2 overexpression deforms nuclear shape and inhibits HIV. J Virol. 2016;90:4199-214.

359. Christ F, Thys W, De Rijck J, Gijsbers R, Albanese A, Arosio D, Emiliani S, Rain JC, Benarous R, Cereseto A, Debyser Z. Transportin-SR2 imports HIV into the nucleus. Curr Biol. 2008;18:1192-202.

360. Logue EC, Taylor KT, Goff PH, Landau NR. The cargo-binding domain of transportin 3 is required for lentivirus nuclear import. J Virol. 2011:85(24):12950-61.

\section{Publisher's Note}

Springer Nature remains neutral with regard to jurisdictional claims in published maps and institutional affiliations. 